ALEXANDRE MAGNO LIMA CARDOSO

ESTUDO DA RIGIDEZ EFETIVA DO CABO DE PONTE ESTAIADAS

São Carlos

2013 



\section{ESTUDO DA RIGIDEZ EFETIVA DO CABO DE PONTES ESTAIADAS}

\section{Versão Corrigida}

A versão original encontra-se na Escola de Engenharia de São Carlos

Dissertação apresentada ao Departamento de Engenharia de Estruturas da EESC-USP como parte dos requisitos necessário à obtenção do título de Mestre em Engenharia de Estruturas.

Orientador: Prof. Dr. José Elias Laier

UNIVERSIDADE DE SÃO PAULO ESCOLA DE ENGENHARIA DE SÃO CARLOS

São Carlos

2013 
AUTORIZO A REPRODUÇÃO TOTAL OU PARCIAL DESTE TRABALHO, POR QUALQUER MEIO CONVENCIONAL OU ELETRÔNICO, PARA FINS DE ESTUDO E PESQUISA, DESDE QUE CITADA A FONTE.

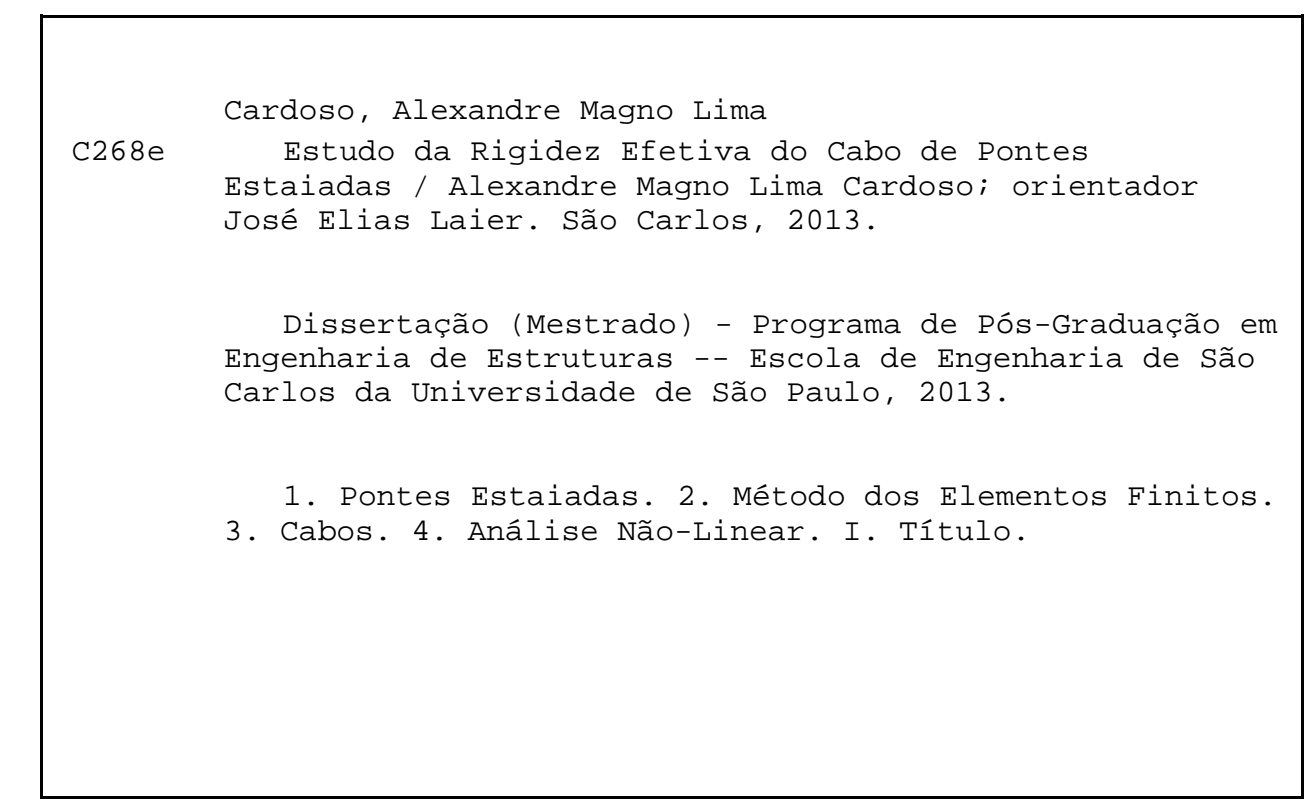




\section{FOLHA DE JULGAMENTO}

Candidato: Bacharel ALEXANDRE MAGNO LIMA CARDOSO.

Título da dissertação: "Estudo da rigidez efetiva do cabo de pontes estaiadas".

Data da defesa: 04/12/2013

\section{Comissão Julgadora:}

Prof. Titular José Elias Laier (Orientador)

(Escola de Engenharia de São Carlos/EESC)

Prof. Dr. Edson Denner Leonel

(Escola de Engenharia de São Carlos/EESC)

Prof. Dr. Rui Nobhiro Oyamada

(Escola Politécnica/USP)

\section{Resultado:}

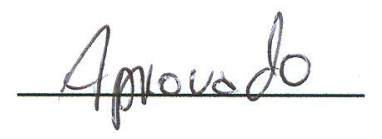

APROUADO

Coordenadora do Programa de Pós-Graduação em Engenharia Civil (Engenharia de Estruturas):

Profa. Associada Ana Lucia Homce de Cresce El Debs

Presidente da Comissão de Pós-Graduação:

Prof. Titular Denis Vinicius Coury 
Dedico este trabalho a minha família e com muito carinho à minha esposa Carolina. 



\section{AGRADECIMENTOS}

Agradeço à minha família por todo apoio, carinho e incentivo que foram dados em toda minha vida.

Agradeço à minha esposa Carolina, meu porto seguro, por todo carinho e apoio que foi dado durante esta busca.

Agradeço ao meu amigo Professor Leon, sempre em contato, pelos ensinamentos acadêmicos na graduação e principalmente pelas suas palavras de incentivo e sabedoria.

Aos meus amigos da turma de SET, companheiros de mestrado, agradeço por tudo que aprendi com vocês na nossa busca pelo conhecimento, pelo carinho e cuidados nos tempos difíceis e pelos divertidos e inesquecíveis momentos que passamos em São Carlos.

Aos meus amigos David e Marcos pelo grande apoio na reta final desse trabalho.

Agradeço ao meu orientador José Elias Laier pelo voto de confiança e a ajuda necessária para realização deste trabalho.

Agradeço ao CNPq pela bolsa de mestrado concedida, à Universidade de São Paulo - Escola de Engenharia de São Carlos pela acolhida e a Universidade Federal de Roraima pela formação. 

"Só sei que nada sei"

Socrates 



\section{RESUMO}

CARDoso, A. M. L. (2013). Estudo da rigidez efetiva do cabo de pontes estaiadas. Dissertação (Mestrado) - Escola de Engenharia de São Carlos, Universidade de São Paulo São. Carlos. 2013

As pontes estaiadas vêm sendo cada vez mais utilizadas no país, seja pela competitividade alcançada em função do domínio da tecnologia por parte dos empreiteiros e calculistas, seja pelo apelo estético. Os cabos, principais componentes deste sistema estrutural, que conferem o caráter altamente hiperestático e o comportamento não linear da estrutura são, em muitos modelos, numericamente simulados como um elemento de treliça, com a sua rigidez calculada em função da geometria e nível de carregamento do cabo.

No presente trabalho é verificada a influência da componente tangencial do peso próprio do cabo, desprezada por Dishinger no cálculo da rigidez equivalente do elemento de cabo, comparada com o método proposto por Hajdn. Os resultados também são comparados com os da modelagem do cabo discretizado em elementos de treliça, seguindo a Formulação Posicional dos Elementos Finitos, que se mostrou bastante eficaz para simulação do cabo isolado, onde a capacidade de representar o comportamento do cabo foi verificada através de exemplos que mostram aspectos do comportamento não linear do mesmo.

Palavras-Chave: Pontes Estaiadas, Cabos, Elementos Finitos 



\section{ABSTRACT}

CARDOSO, A. M. L. (2013). STUDY OF THE EFFECTIVE STIFFNESS OF A CABLE OF CABLE STAYED BRIDGES. MSc.. Thesis - Escola de Engenharia de São Carlos, Universidade de São Paulo. São Carlos. 2013.

Cable stayed bridges are being increasingly used in Brazil due to the recent master on this technology by the builders and designers and because of its aesthetics appealing. The principal components of this type of bridge, the cables, responsible for high non-linear behavior of the structure, are frequently modeled as truss element with its stiffness evaluated according to the tension and horizontal projection of the span of the cable.

On the present paper the influence by neglecting the tangential component of the weight of the cable on Dishinger's formula is investigated. The results are compared with the formula by Hajdn and with a model in which the cable is discretized in truss bars in a program based on the Positional Finite Element Method which has presented good results to describe the non-linear behavior of the cable.

Keywords: Cable stayed bridges, Cables, Finite Elements 



\section{LISTA DE FIGURAS}

Figura 1 - Ilustração de Navier para pontes estaiadas -1823 ....................... 7

Figura 2 - Ponte Porto Alencastro, Mato Grosso do Sul ........................... 8

Figura 3 - Ponte Engenheiro Jamil Sabino, São Paulo............................... 9

Figura 4 - Ponte sobre o Rio Guamá, Belém ........................................ 10

Figura 5 - Passarela Estaiada em Rio Branco, Acre .............................. 11

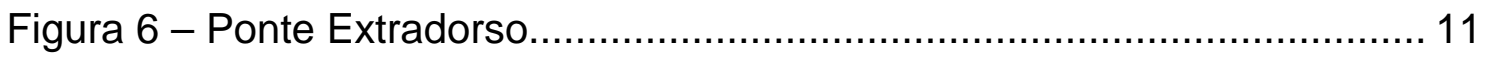

Figura 7 - Ponte Octavio Frias de Oliveira ..................................... 12

Figura 8 - Componentes da ponte estaiada .................................... 13

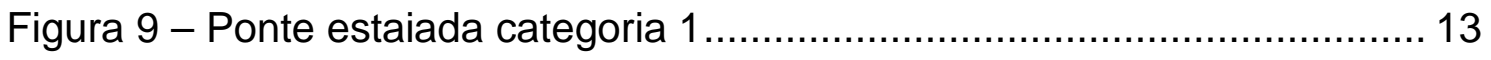

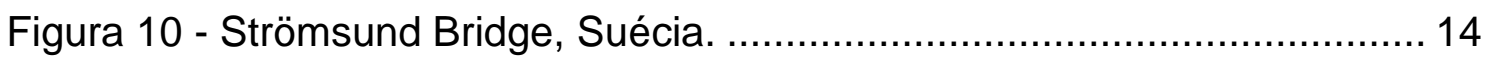

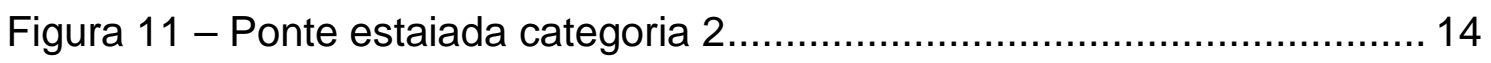

Figura 12 - Minpu Bridge, Shangai ............................................... 15

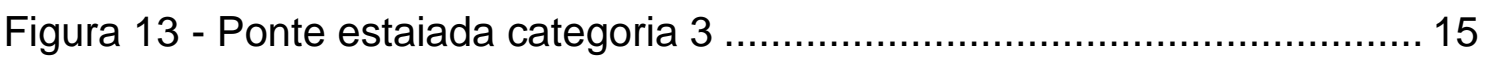

Figura 14 - Erasmus Bridge, Holanda ............................................ 16

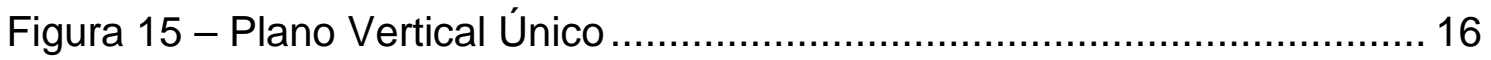

Figura 16 - Dois ou mais Planos Verticais ......................................... 17

Figura 17 - Planos Inclinados ................................................. 18

Figura 18 - Distribuição Longitudinal do cabos................................... 18

Figura 19 - Suspensão Catenária .......................................................... 20 
Figura 20 - Sistema de eixos para parametrização das equações

Figura 21 - Gráfico Parábola vs. Catenária

Figura 22 - Cabo Inclinado 24

Figura 23 - Diferença entre catenária e parábola 26

Figura 24 - Diagrama de corpo livre para obtenção do Módulo de Hajdin....... 27

Figura 25 - Diagrama de corpo livre da metade do cabo 28

Figura 26 - Deslocamento do elemento infinitesimal do cabo 29

Figura 27 - Deformação de Green x Deformação Linear 33

Figura 28 - Diferença \% entre Green e deformação Linear. 33

Figura 29 - Configuração indeformada X e atual $\mathbf{Y}$ do elemento de treliça ...... 34

Figura 30 - Forças internas - Graus de Liberdade do Elemento de treliça ...... 36

Figura 31 - Fluxograma - Programa para Análise Não Linear Geométrica com a formulação Posicional do Elementos Finitos. 38

Figura 32 - Cabo pré-tensionado sob ação de carga distribuída 39

Figura 33 - Deslocamento em função do acréscimo de carga distribuída. 41

Figura 34 - Cabo suspenso com carga concentrada

Figura 35 - Deslocamento do ponto de aplicação da carga 43

Figura 36 - Deformada do cabo conforme aumento da carga pontual 44

Figura 37 - Incremento de deslocamento no cabo do modelo em elementos finitos 46

Figura 38 - Variação do módulo de rigidez equivalente para inclinação $0^{\circ}$ 47 
Figura 39 - Variação do módulo de rigidez equivalente para inclinação $10^{\circ} \ldots 48$

Figura 40 - Variação do módulo de rigidez equivalente para inclinação $20^{\circ} \ldots 49$

Figura 41 - Variação do módulo de rigidez equivalente para inclinação $30^{\circ} \ldots 49$

Figura 42 - Variação do módulo de rigidez equivalente para inclinação $45^{\circ} \ldots 50$

Figura 43 - Variação do módulo de rigidez equivalente para inclinação $60^{\circ} \ldots 51$

Figura 44 - Variação do módulo de rigidez equivalente para inclinação $75^{\circ} \ldots 51$ 



\section{LISTA DE TABELAS}

Tabela 1 - Vantagens e desvantagens dos arranjos mais comuns dos estais 19

Tabela 2 - Variação do comprimento total do cabo em função da intensidade

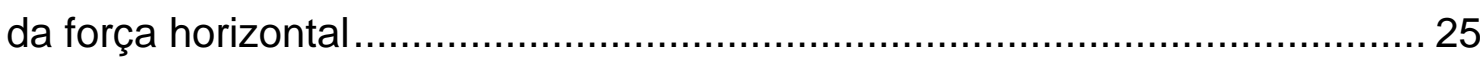

Tabela 3 - Flechas do cabo pré-tensionado ………….............................. 40

Tabela 4 - Deslocamentos no ponto de aplicação da carga em metros .......... 43 



\section{SUMÁRIO}

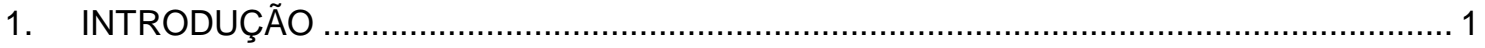

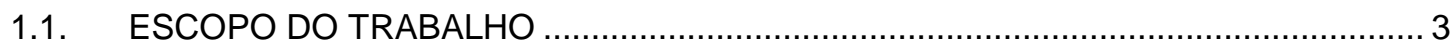

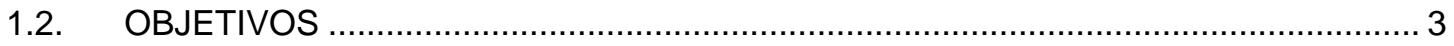

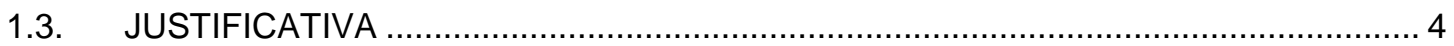

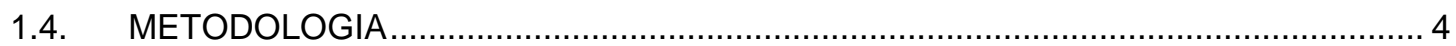

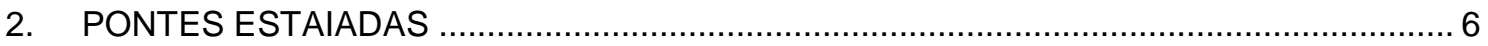

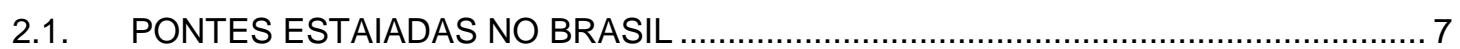

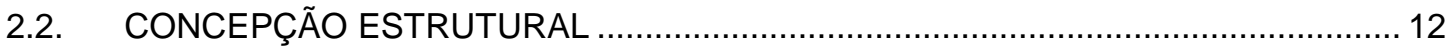

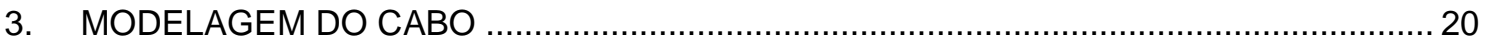

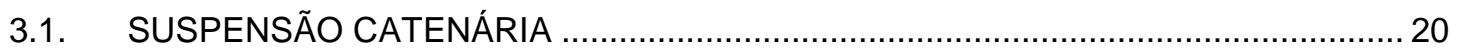

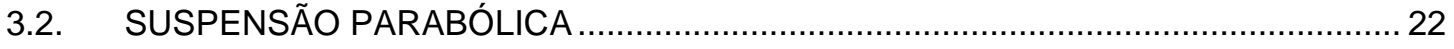

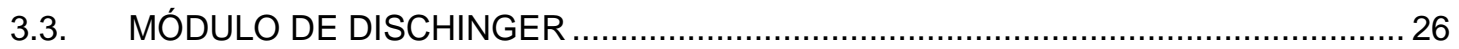

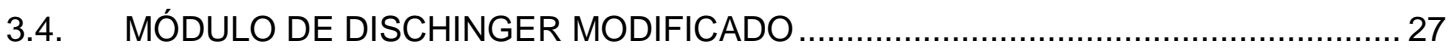

4. ANÁLISE NÃO LINEAR GEOMÉTRICA BASEADA NA FORMULAÇÃO POSICIONAL DO

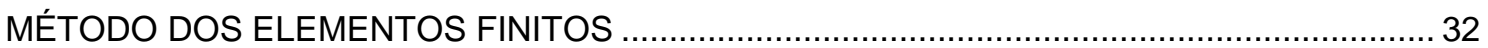

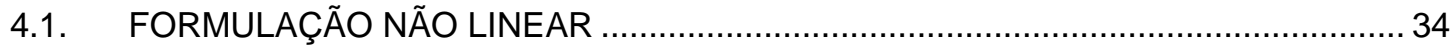

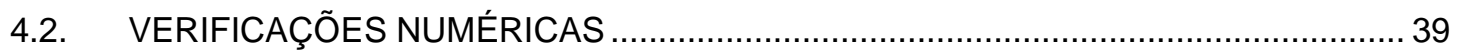

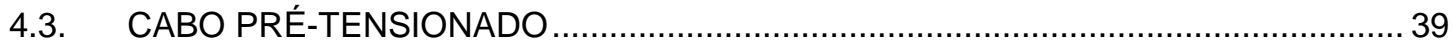

4.4. CABO SUSPENSO COM CARGA CONCENTRADA …............................................ 42

5. ESTUDO COMPARATIVO DA VARIAÇÃO DO MÓDULO DE RIGIDEZ EM FUNÇÃO DA

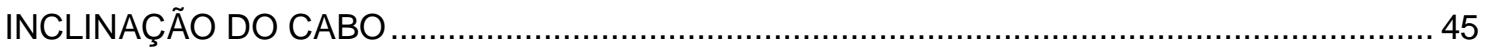

5.1. OBTENÇÃO DO MÓDULO DE RIGIDEZ EQUIVALENTE COM OS MÓDULOS DE DISHINGER E HAJDIN .....

5.2. OBTENÇÃO DO MÓDULO DE RIGIDEZ EQUIVALENTE A PARTIR DO MODELO

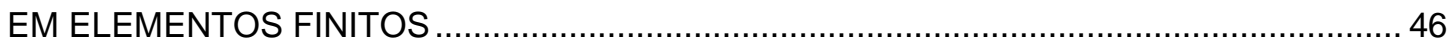

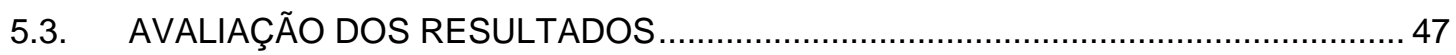

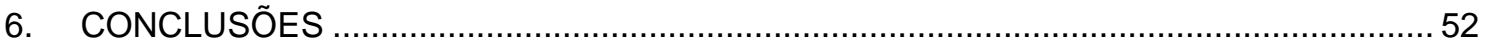

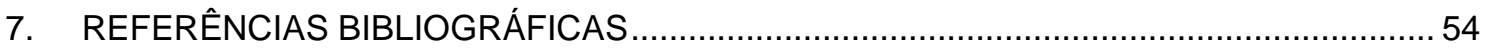





\section{INTRODUÇÃO}

Desde a antiguidade há a necessidade de transpor grandes obstáculos, seja para a busca de abrigo ou alimento. A observação da natureza provavelmente foi a inspiração dos primeiros construtores na concepção dos artefatos que hoje chamamos de pontes.

A utilização dos cabos para construção de pontes pode ser uma das técnicas mais primitivas de construção. Embora a maioria destas pontes pênseis flexíveis fossem elaboradas com cordas, há registros de pontes com correntes de ferro feitas na China muito antes da era cristã (PAULETTI, 2003).

As grandes pontes surgiram durante a revolução industrial. $O$ aumento da demanda devido ao acelerado processo de urbanização e necessidade de escoamento da produção estimulou o desenvolvimento de métodos e materiais mais eficientes, bem como teorias que permitissem avanços na tecnologia de construção.

Logo surgiram as pontes pênseis, apresentando vantagens de custo sobre as outros sistemas estruturais da época pois aproveitavam bem a trabalhabilidade e resistência do ferro forjado para fabricação de correntes metálicas de grande eficiência estrutural. A facilidade de construção e a capacidade de vencer grandes vão eram as grandes vantagens destes sistemas. A única grande desvantagem desse sistema estrutural era a forma catenária do tabuleiro e os grandes deslocamentos frente a cargas concentradas, impedindo a operação da ponte para veículos pesados. Somente em 1796, quando Finley construiu a primeira ponte suspensa com tabuleiro rígido plano, que as pontes suspensas foram aceitas como solução para transposição de grandes vãos para trafego de veículos pesados.

As pontes estaiadas, apesar de consideradas mais estáveis do que as pontes pênseis, tiveram seu desenvolvimento coibido em função de alguns fracassos nas tentativas de execução (PAULETTI, 2003).

Um estudo feito pelo engenheiro Claude Louis Marie Henri Navier encomendado pelo governo francês para estudar as pontes inglesas, tido por muito 
tempo como absoluto sobre pontes suspensas, não recomendava a utilização de pontes estaiadas.

Somente após estudos realizados por F. Dishinger é que as pontes estaiadas voltaram a ser consideradas.

Atualmente, o constante desenvolvimento de materiais, bem como dos métodos construtivos, tem sido fundamental para viabilizar projetos de pontes estaiadas, tornando viáveis e competitivos tanto os projetos de menor porte como os mais arrojados. Este sistema estrutural tem sido adotado cada vez mais como solução em projetos rodoviários, com destaque no sistema viário urbano, onde a construção não pode causar interrupção no fluxo do tráfego, exigindo grandes vãos livres. Nesse sentido vale registrar que segundo o presidente da Associação Brasileira de Pontes e Estruturas ABPE, Gilberto Barbosa do Valle (2010), a principal tendência para construção de pontes no Brasil, no momento, é o emprego crescente das pontes estaiadas. Ainda segundo ele, no Brasil podem-se destacar as recentes obras de pontes como a Octavio Frias de Oliveira, na cidade de São Paulo, a ponte Rio Negro-Aranduba, no estado do Amazonas, e a ponte sobre o Rio Poty, no estado do Piauí. Tais obras, como se sabe, tornaram-se referência no Brasil e também no mundo.

Segundo Gatulli (2008), o desenvolvimento tecnológico tem permitido a concepção de estruturas mais leves e flexíveis, que são características desejáveis. Essa características, porém, vêm acompanhadas de outros efeitos, entre eles grandes deslocamentos, que devem ser analisados com mais critério.

A análise de estruturas com cabos apresenta grande complexidade, pois a relação tensão-deformação do cabo é altamente não linear. Somado a isso têm-se também os efeitos da não linearidade geométrica causada pelas grandes deformações inerentes a sistemas estruturais com cabos. (PEYROT, 1978). Assim, utilizam-se técnicas numéricas para a descrição desta relação não linear, onde o método dos elementos finitos é amplamente utilizado. Assim como para todos os elementos estruturais, segundo Peyrot (1978), existem diversos modelos para o elemento finito de cabo. 
No caso de estruturas usuais, sujeitas a pequenas deformações e pequenos deslocamentos, onde a geometria original do sistema se mantém praticamente inalterada na análise, é bastante comum a simulação dos cabos por uma série de elementos de treliça; resolvendo-se assim o problema estrutural mediante uma análise não-linear geométrica.

Este estudo se concentra em comparar formas de modelagem para a simulação do comportamento dos cabos de uma estrutura estaiada, que é o elemento principal neste sistema estrutural.

\subsection{ESCOPO DO TRABALHO}

A não linearidade do cabo será analisada apenas do ponto de vista geométrico utilizando três formulações distintas.

A primeira, proposta por Dischinger (1949), é tradicionalmente usada nos modelos de pontes estaiadas. O cabo é formulado como um elemento de treliça com o módulo de rigidez modificado em função da tensão e da projeção horizontal do cabo.

A segunda formulação, proposta por Hajdin (1998), consiste num aperfeiçoamento da primeira, na qual uma das simplificações feitas por Dischinger (1949) para obtenção da formula é então desconsiderada.

A terceira consiste no emprego da formulação posicional do Método dos Elementos Finitos (MEF), Coda (2005), objetivando uma simulação do cabo segundo uma série de elementos de treliça.

\subsection{OBJETIVOS}

É estudado o comportamento mecânico dos elementos de cabo proposto por Dischinger (1949) e Hajdin (1998) comparados com um modelo com barras de treliça segundo a formulação posicional do MEF, proposto por Coda (2005).

Este trabalho tem como objetivo geral identificar e quantificar a influência da inclinação do cabo em resultados obtidos segundo as três formas de modelagem do cabo estudadas. 


\subsection{JUSTIFICATIVA}

O constante desenvolvimento de novos materiais, bem como de métodos construtivos, permite a arquitetos e engenheiros a elaboração de projetos mais arrojados com aproveitamento ao máximo da capacidade dos materiais.

Em muitas dessas estruturas surgem efeitos mecânicos indesejáveis, em função da flexibilidade e do grau de hiperestaticidade das estruturas estaiadas. Estes efeitos devem ser estudados e levados em conta na fase de projeto para evitar gastos excessivos com manutenção e reforços, e mais importante, conferindo mais segurança prevenindo a ocorrência de sinistros.

O estudo da abrangência da modelagem dos elementos é importante para avaliar o quão próximo da realidade estão os modelos propostos. Desta forma, os modelos não lineares, apesar de onerosos em termos computacionais, tendem a ser mais fiéis ao comportamento real da estrutura.

É importante conhecer as limitações dos modelos para que os projetistas possam contar com ferramentas mais requintadas tanto na fase de estudos preliminares como na implantação do projeto da estrutura.

\subsection{METODOLOGIA}

O estudo será desenvolvido através da implementação computacional dos modelos propostos por Dischinger, Hajdin e utilizando o MEF Posicional (CODA, 2005), onde os três modelos serão comparados.

É verificada a influência da inclinação do cabo na variação do módulo de elasticidade equivalente.

Utilizando-se da formulação de suspensão parabólica para a geometria curva do cabo, em função de uma determinada flecha, vão e inclinação, é obtida a tensão no cabo compatível com tal configuração.

A partir de determinado valores para uma dada configuração inicial do cabo, é então obtido o módulo de elasticidade equivalente àquela configuração do cabo com 
a formulação proposta por Dischinger (1949) e com a modificada proposta por Hajdin (1998). De antemão do valor da rigidez do cabo é calculada a força necessária para um determinado passo de deslocamento na direção axial do elemento. Desta forma são obtidos os dados para atualização do módulo de elasticidade equivalente do cabo, em cada uma das formulações, para o próximo passo de deslocamento.

Já para o modelo desenvolvido segundo a formulação posicional do MEF, o cabo é então discretizado segundo a curva descrita pela aproximação parabólica da catenária, sendo o peso próprio considerado com forças nodais equivalentes compatíveis.

Com a configuração inicial determinada é realizada uma série de deslocamentos de apoio em uma das extremidades do cabo, na direção do eixo entre os apoios.

Com o controle de deslocamentos é obtida a tensão no meio do cabo para cada configuração, e, de posse destes valores é calculado um módulo de rigidez equivalente para o deslocamento naquela direção.

Os valores obtidos são apresentados em gráficos de modo a permitir uma comparação entre os resultados oferecidos pelos três modelos aqui considerados. 


\section{PONTES ESTAIADAS}

Esta revisão bibliográfica apresenta alguns conceitos e informações importantes para o pleno desenvolvimento da dissertação.

Segundo Pauletti (2003), nos estudos iniciais para concepção do sistema estrutural de pontes suspensas por cabos as pontes estaiadas eram tidas como mais estáveis que as pontes pênseis. Entretanto, alguns fracassos acabaram desencorajando o desenvolvimento das pontes estaiadas.

De acordo com Billington (1992), Navier declarava que as pontes estaiadas eram inadequadas para grandes vãos, o que ajudou a coibir o desenvolvimento deste modelo estrutural. Em seu estudo conhecido como Memoire de Navier, afirmava que a relação ótima entre a altura do mastro e o vão principal deveria ser de aproximadamente $1 / 2,28$, fator este que tornaria as pontes estaiadas antieconômicas para grandes vãos, e se posicionou notoriamente contra a concepção deste modelo estrutural.

Observando a concepção de Navier apresentada por Billington (1992), dada na Figura 1, percebe-se que a relação entre o mastro e o vão é bem maior do que nos projetos atuais.

Outro fator que acarretou a estagnação no desenvolvimento das pontes estaiadas na época é que para o funcionamento adequado do sistema estrutural estaiado o nível de tracionamento dos cabos é muito mais elevado do que nos sistemas pênseis, esforço inadequado para as correntes de ferro forjado disponível à época.

O uso das correntes era inviável, pois o peso próprio era muito elevado devido às grandes seções transversais necessárias devido a baixa resistência do ferro. Desta forma os cabos perdiam rigidez em função da flecha assumida pelo mesmo. 

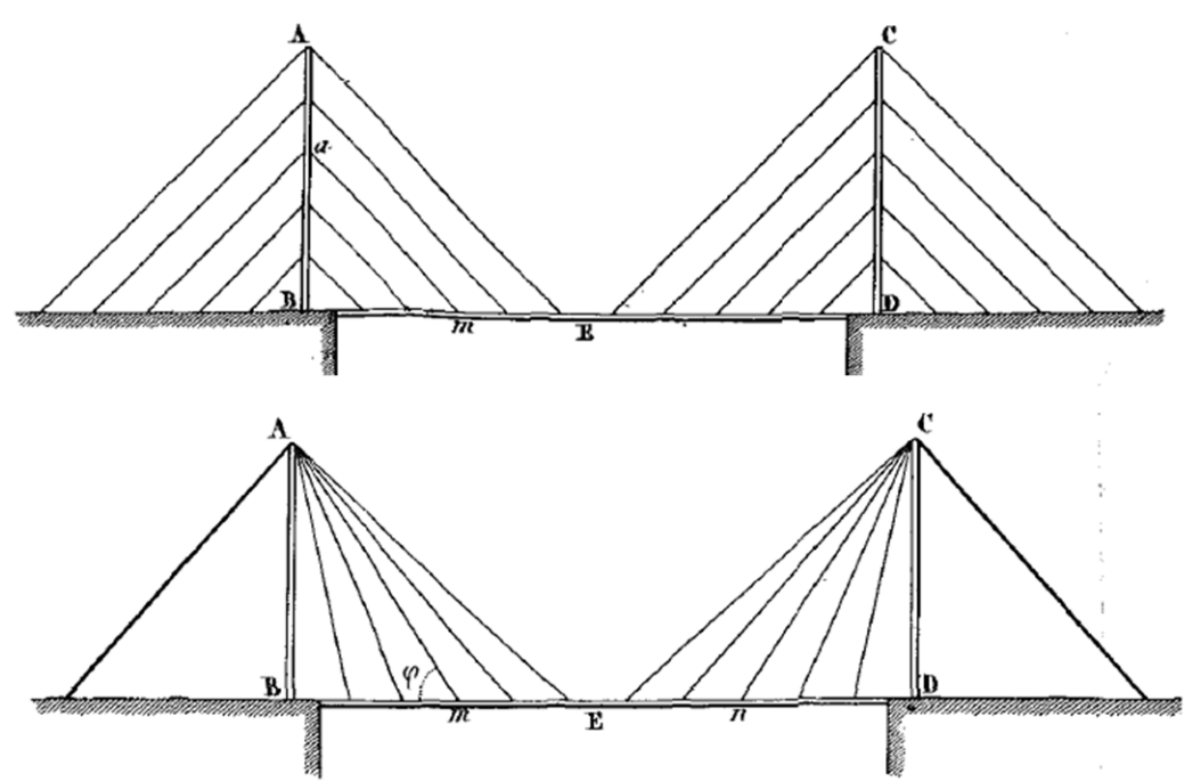

Figura 1 - Ilustração de Navier para pontes estaiadas - 1823

(fonte: Bilington, 1988)

O desenvolvimento das pontes estaiadas só foi retomado quando o engenheiro F. Dischinger demonstrou em seus estudos que as deflexões assumidas pelas pontes pênseis poderiam ser reduzidas com o emprego de estais confeccionados com aço de alta resistência.

Os estudos de F. Dischinger tornaram a utilização de pontes suspensas viável para o uso ferroviário, e foram muito aplicados na reconstrução das pontes da Alemanha destruídas durante a segunda guerra mundial (PAULETTI, 2003).

O aprimoramento dos materiais e métodos empregados na construção bem como o avanço nas ferramentas matemáticas computacionais tem tornado os projetos de pontes estaiadas cada vez mais eficientes e competitivos.

\subsection{PONTES ESTAIADAS NO BRASIL}

Segundo Mazarim (2011), o uso de pontes estaiadas como solução estrutural no Brasil é recente, assim como o domínio da sua tecnologia por parte das construtoras e escritórios de projetos estruturais. Ainda que muitos projetos sejam 
feitos em parceria com escritórios estrangeiros, o Brasil já começa a tomar lugar de destaque na engenharia com projetos deste tipo.

Ainda segundo Mazarim, o crescimento da utilização das pontes estaiadas no Brasil tem sido estimulado pelo apelo estético desse tipo de ponte, assim como em vários outros lugares do mundo. As pontes estaiadas são utilizadas como uma oportunidade de agregar valor financeiro e cultural onde são construídas, já que a solução muitas vezes não é a mais adequada tecnicamente ou economicamente.

A Ponte de Porto Alencastro foi o primeiro projeto de ponte estaiada no país. Suas obras iniciaram na década de 80 mas apenas foi inaugurada em 2003. A ponte possui vão livre de $350 \mathrm{~m}$ e comprimento total de $662 \mathrm{~m}$ sobre o rio Paranaíba no estado do Mato Grosso do Sul.

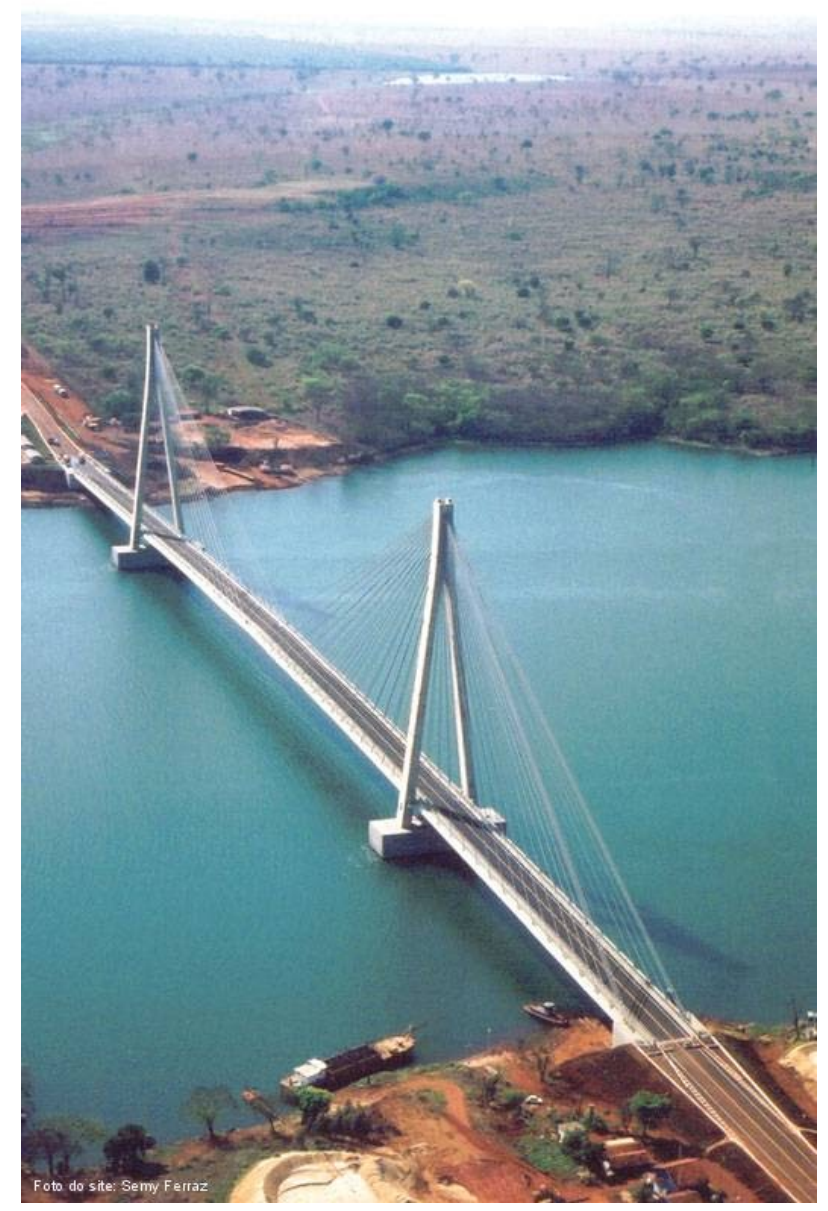

Figura 2 - Ponte Porto Alencastro, Mato Grosso do Sul

(fonte: http://engenhariacivildauesc.blogspot.com.br/2010/10/pontes-estaiadas-nobrasil.html) 
A primeira ponte estaiada inaugurada no país, em 2002, foi a Ponte Estação Metroviária Engenheiro Jamil Sabino, localizada sobre o Rio Pinheiros em São Paulo.

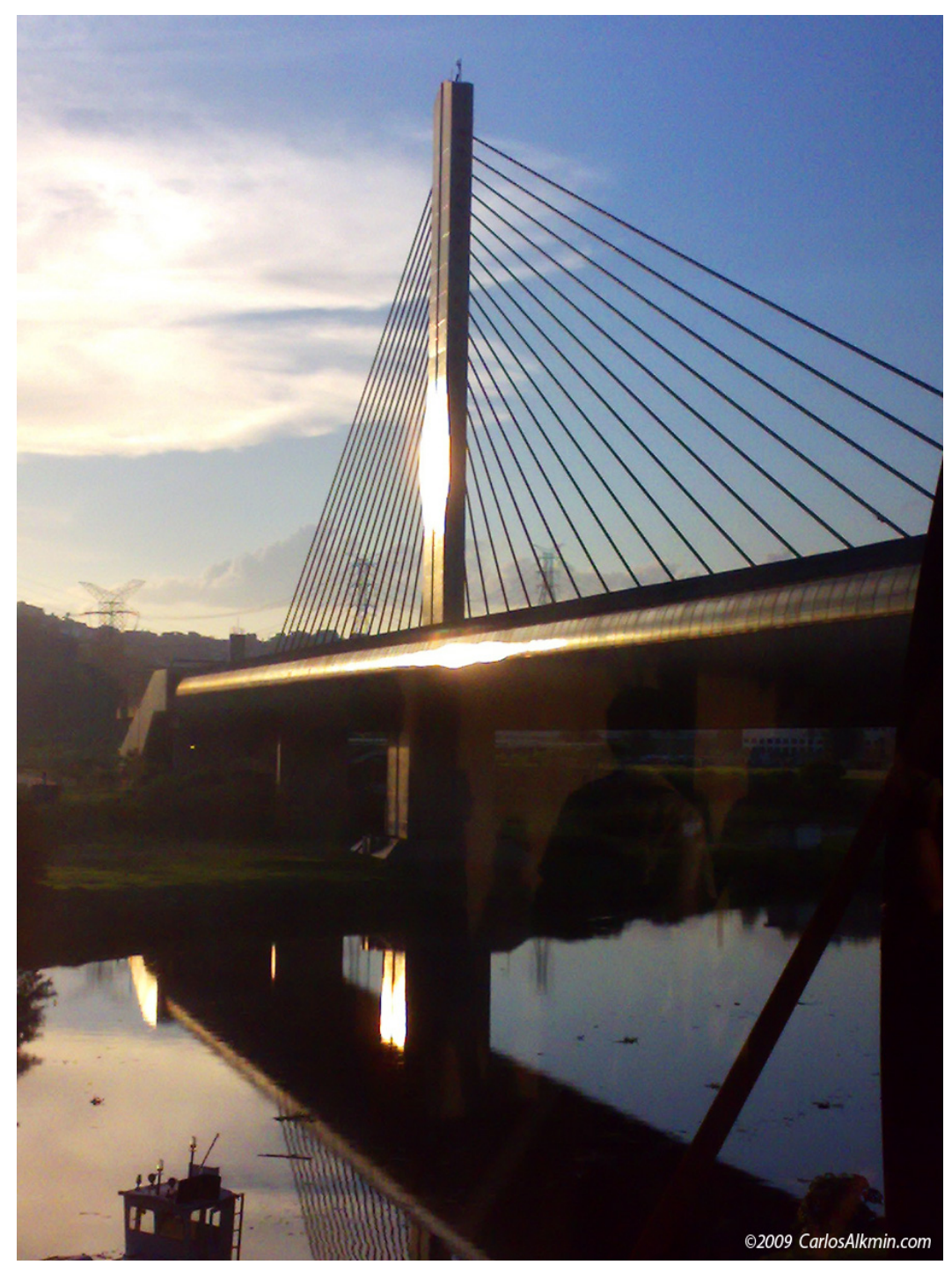

Figura 3 - Ponte Engenheiro Jamil Sabino, São Paulo.

(fonte: http://farm3.staticflickr.com/2686/4078833717_0d8428b111_o.jpg)

Logo uma série de pontes estaiadas começariam a surgir em diversos estados do país. Podem-se destacar alguns projetos como a Ponte sobre o rio Guamá em Belém do Pará, com vão estaiado de 582m, o maior do Brasil, e comprimento total de 1,9Km inaugurada em 2003, a Ponte JK em Brasília e a Ponte 
da Amizade, sobre o Rio Acre, fronteira do Brasil com a Bolívia inauguradas no mesmo ano.

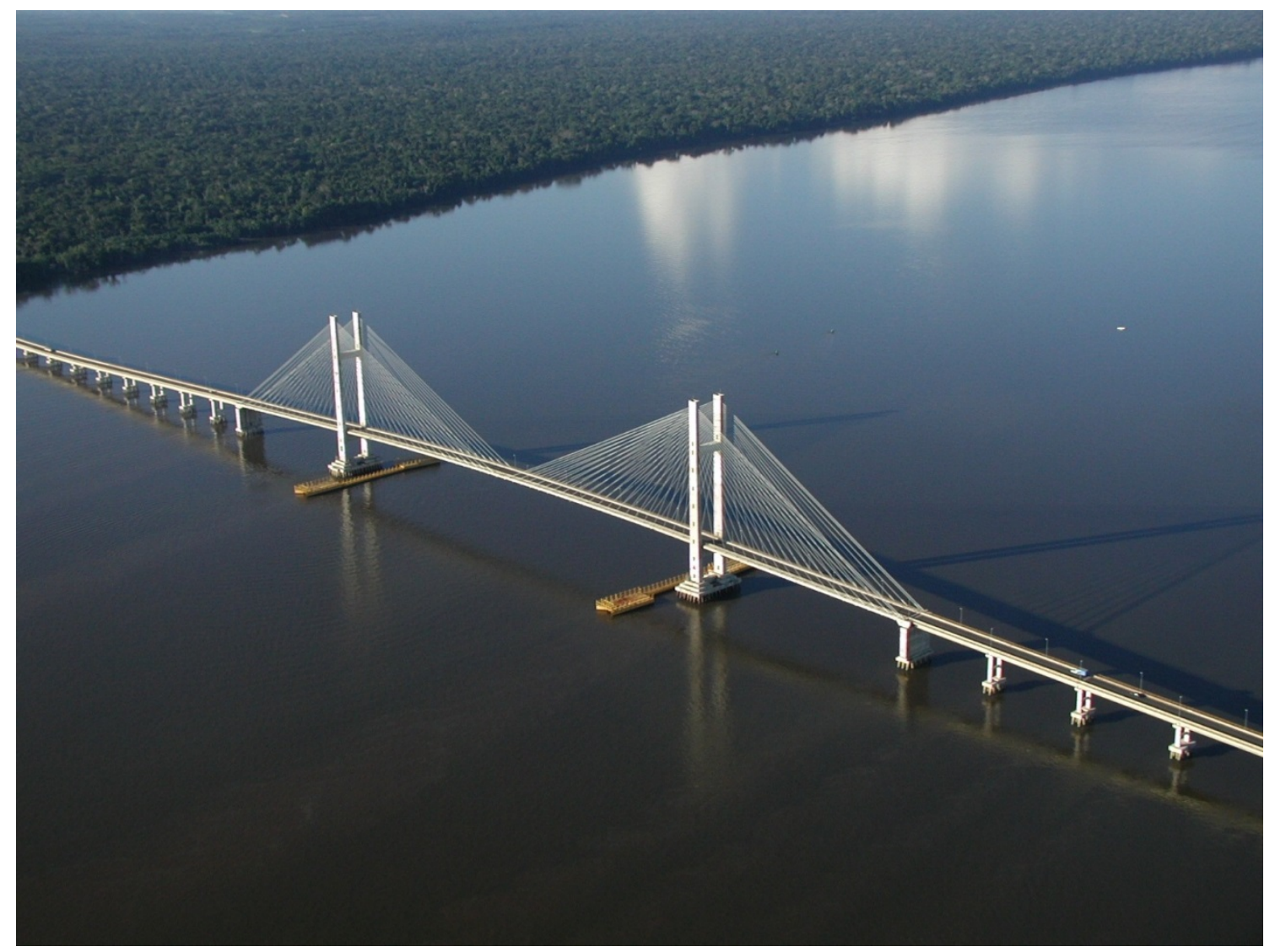

Figura 4 - Ponte sobre o Rio Guamá, Belém

(fonte: http://host3.images.cdn.fotopedia.com/c9o5i05059t3t-JvzZelPzsTQ$\underline{\max 2560 . j p g)}$

No estado do Acre foram realizados diversos projetos de pontes estaiadas. Entre elas a maior passarela estaiada do Brasil inaugurada em 2006, com vão livre de $110 m$ e comprimento total $200 m$ e as primeiras pontes extradorso do país. 


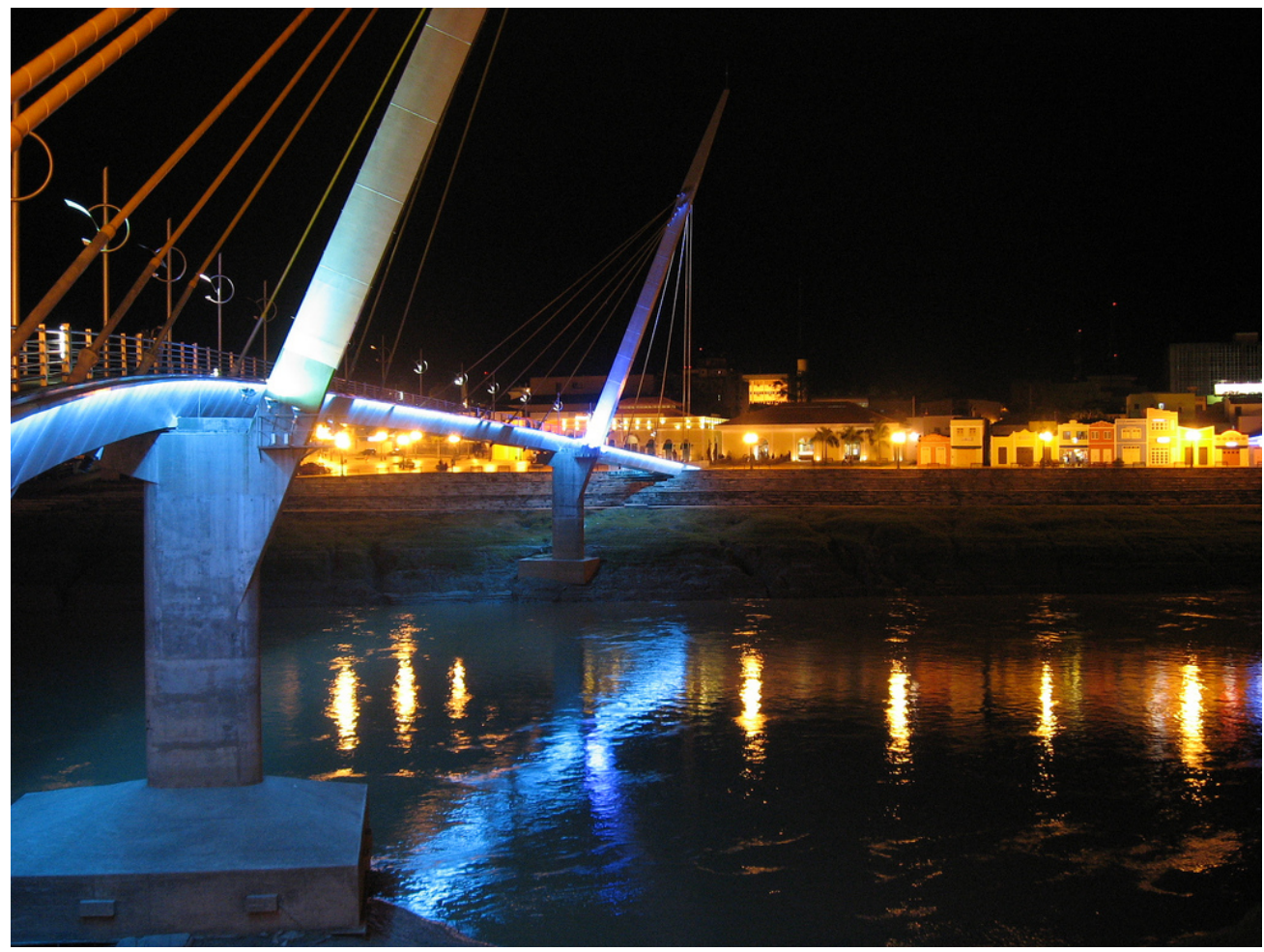

Figura 5 - Passarela Estaiada em Rio Branco, Acre

(fonte: http://www.skyscrapercity.com/showthread.php?t=1592935\&page=6)

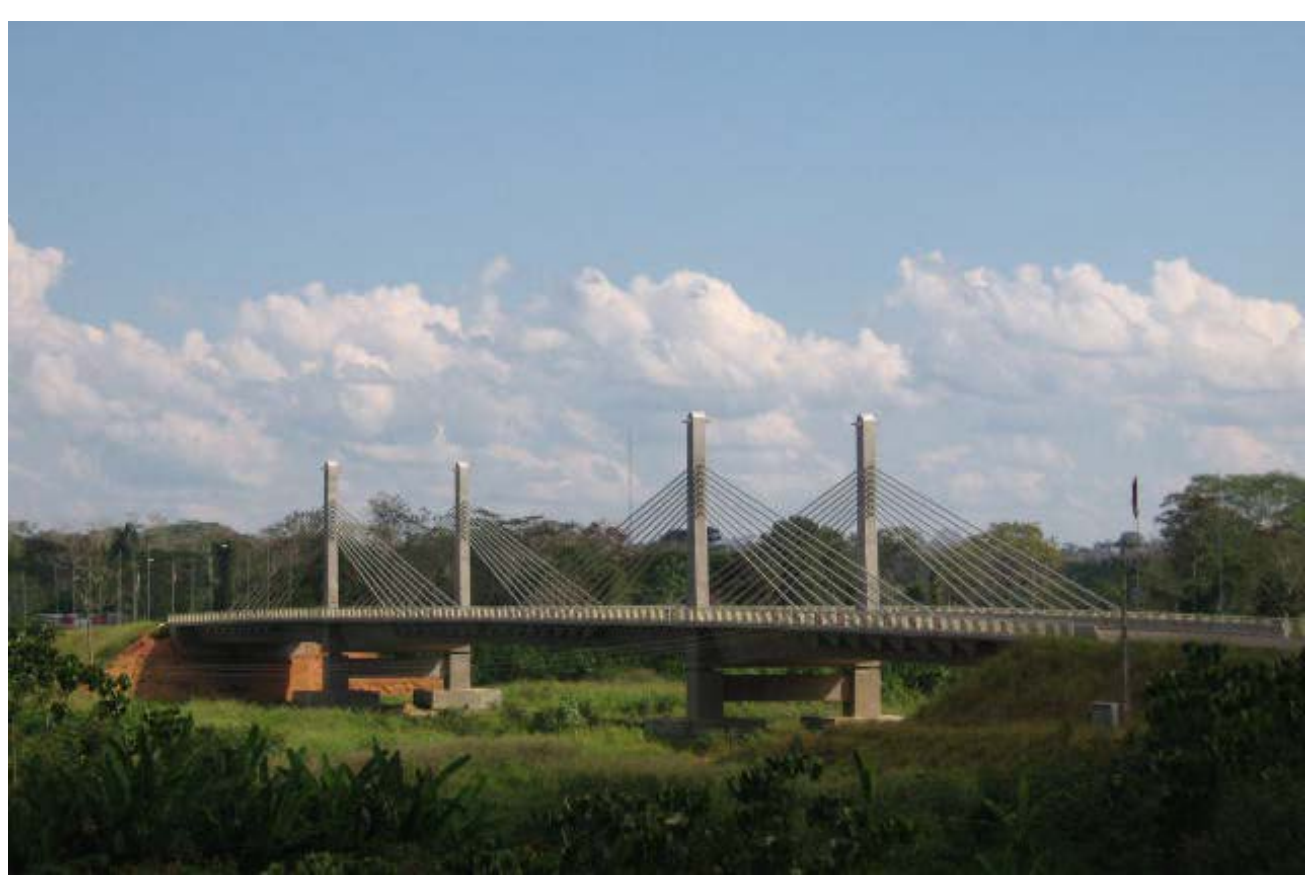

Figura 6 - Ponte Extradorso

(fonte: http://engenhariacivildauesc.blogspot.com.br/2010/10/pontes-estaiadas-nobrasil.html) 
A ponte Octávio frias de Oliveira, sobre o rio Pinheiros, inaugurada em 2008, tem como principal diferencial o mastro em formato de " $\mathrm{X}$ " para sustentar dois tabuleiros curvos.

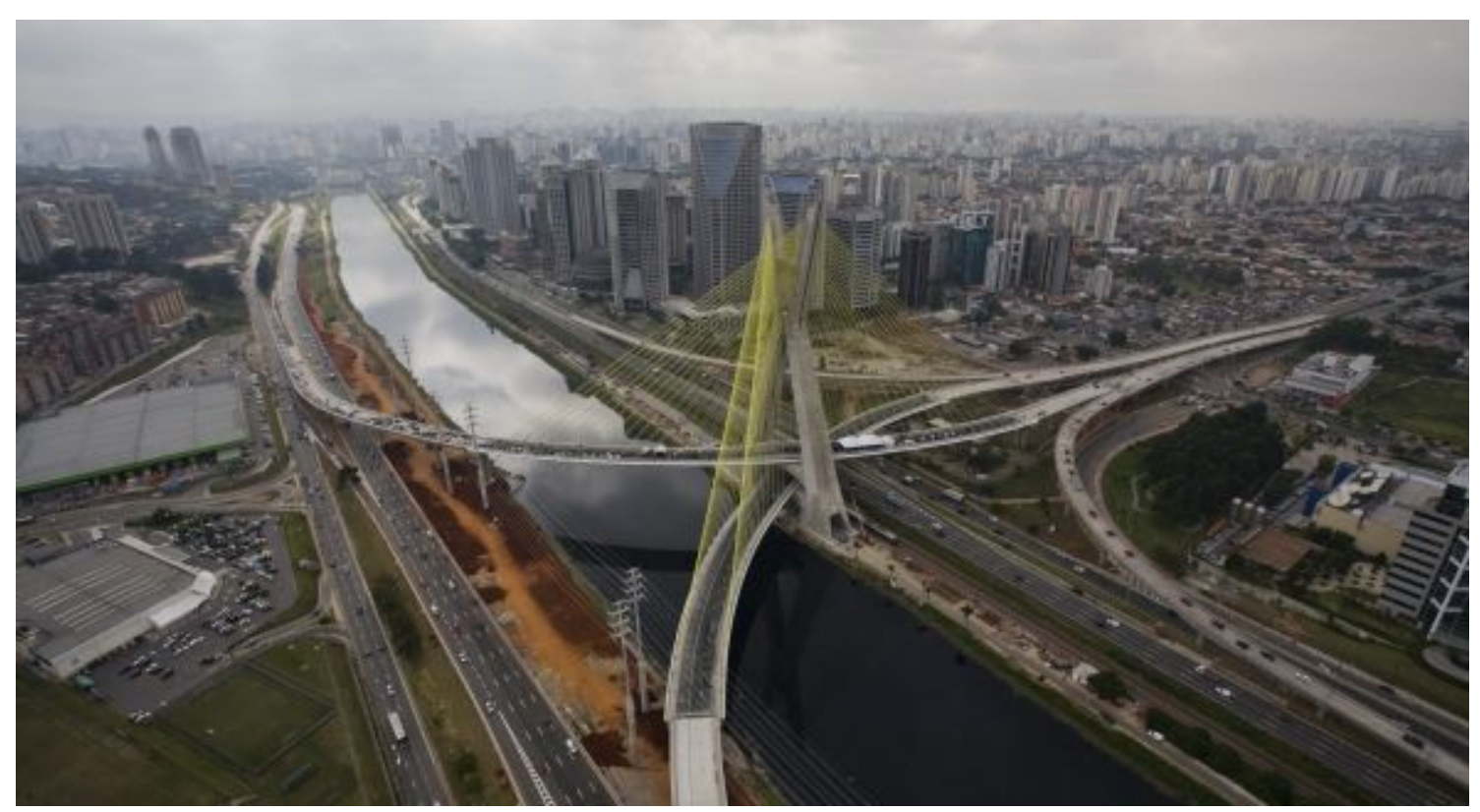

Figura 7 - Ponte Octavio Frias de Oliveira

(fonte: http://engenhariacivildauesc.blogspot.com.br/2010/10/pontes-estaiadas-nobrasil.html)

\subsection{CONCEPÇÃO ESTRUTURAL}

O sistema estaiado pode ser definido em torno de três elementos estruturais principais, o mastro (ou torre), o tabuleiro e o sistema de cabos, ilustrado na Figura 8. 


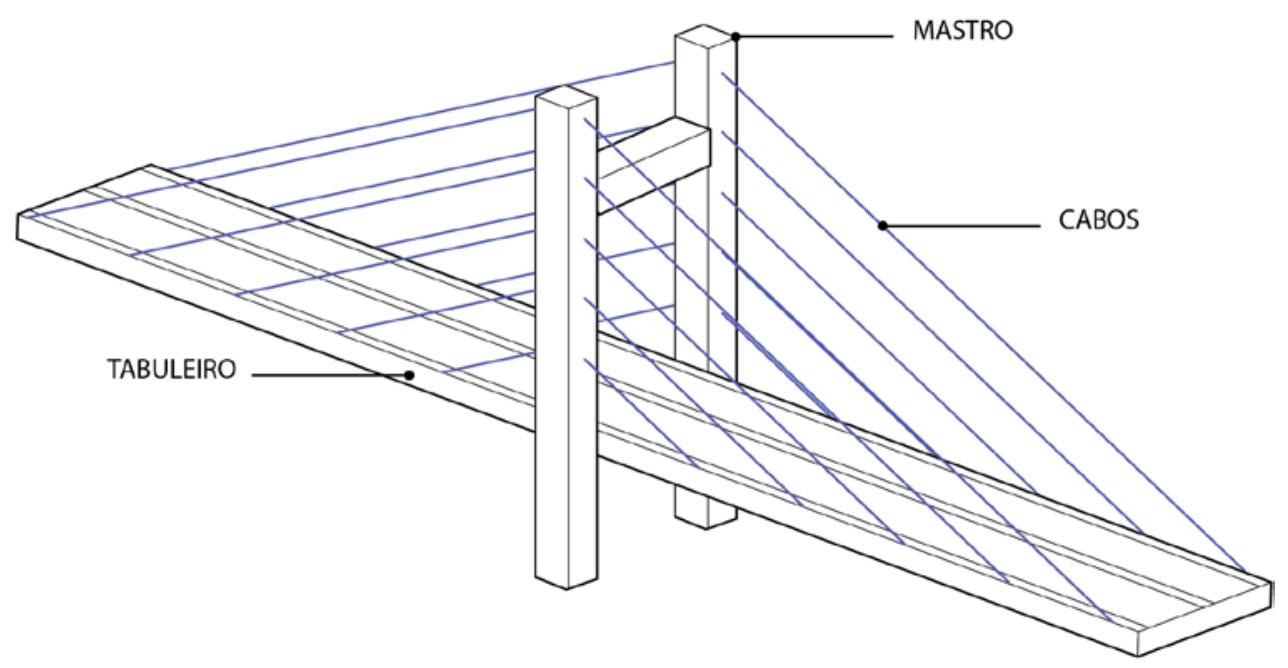

Figura 8 - Componentes da ponte estaiada

O sistema estrutural de uma ponte estaiada pode ser classificado em função dos cabos sobre três aspectos importantes; o espaçamento longitudinal dos estais, a distribuição transversal do estais e a distribuição vertical dos estais.

Mazarim, 2011, apresentou três categorias em função do espaçamento longitudinal dos estais.

As pontes estaiada da categoria 1 possuem vãos simétricos e poucos cabos ao longo do vão, conferindo-lhes um espaçamento grande entre os cabos, conforme pode ser visto na Figura 9.

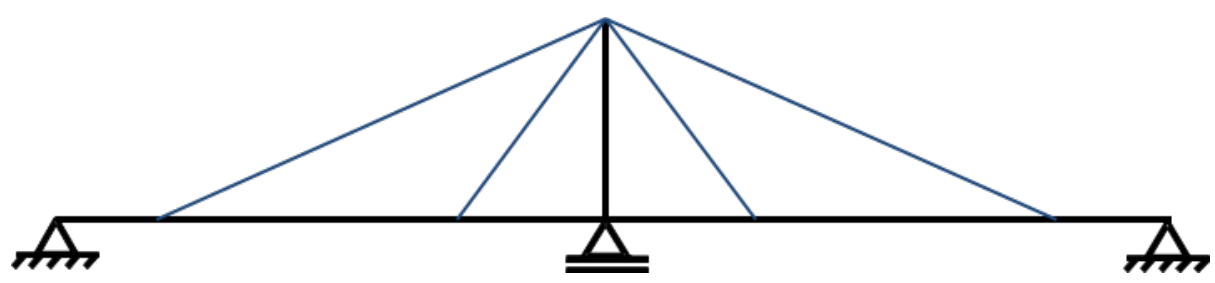

Figura 9 - Ponte estaiada categoria 1

As primeiras pontes estaiadas modernas foram executadas de acordo com essa configuração. O espaçamento grande entre os cabos requer maior rigidez à flexão do tabuleiro e aumenta o esforço em cada cabo, que para atender aos elevados níveis de tensão perdem eficiência devido ao aumento do peso próprio.

Este sistema pode ser utilizado para vão pequenos ou para sistemas com múltiplos tabuleiros estaiados. 
A Strömsund Bridge se encaixa nesta categoria. A ponte, projetada por F. Dischinger,é tida como uma das primeiras pontes estaiadas modernas, inaugurada em 1956 com 182m de vão livre.

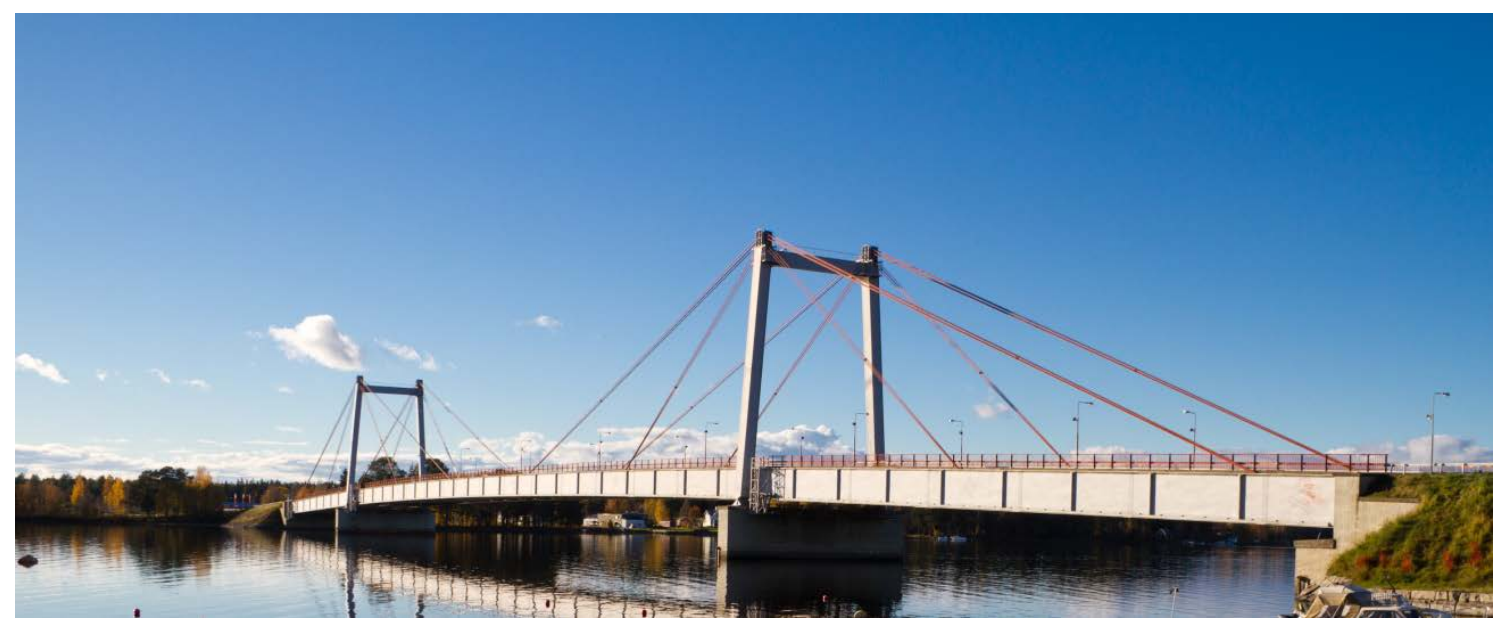

Figura 10 - Strömsund Bridge, Suécia.

(fonte: http://upload.wikimedia.org/wikipedia/commons/b/b9/Str\%C3\%B6 msundsbron 2010.jpg)

$\mathrm{Na}$ Categoria 2, ilustrada na Figura 11, há um maior número de estais distribuídos ao longo do vão o que permite a construção de um tabuleiro mais esbelto já que a proximidade dos pontos de suspensão da carga diminuem significativamente os esforços de flexão no tabuleiro.

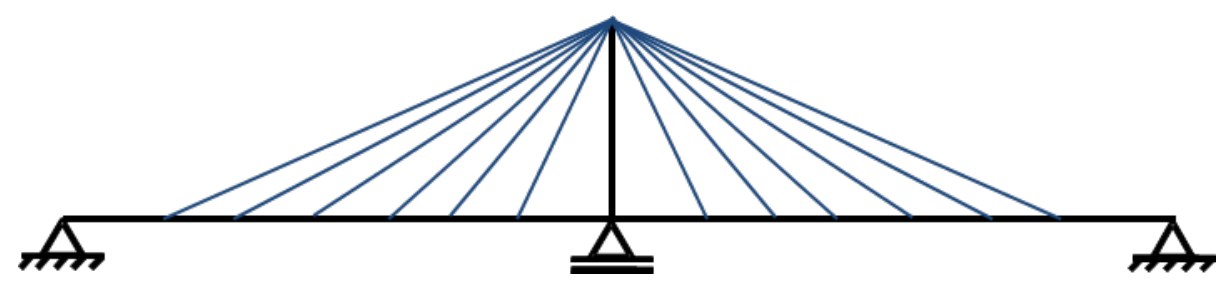

Figura 11 - Ponte estaiada categoria 2

A maioria das pontes estaiadas mais recentes se encaixam nesta categoria como a Minpu Bridge, inaugurada em 2010 em Shangai. 


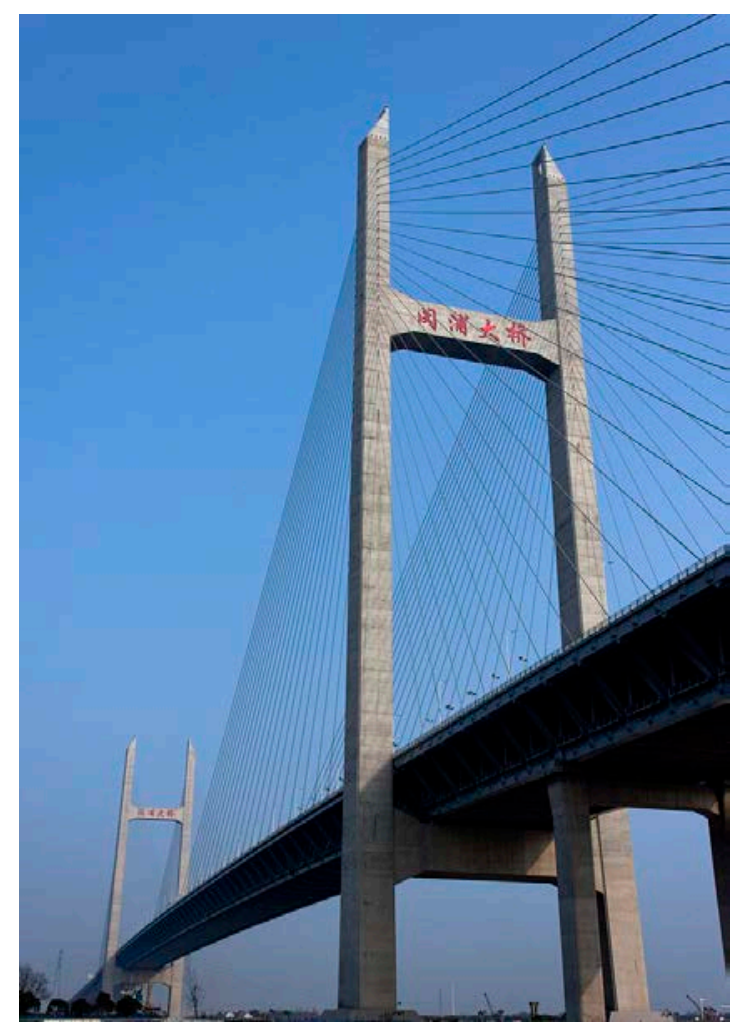

Figura 12 - Minpu Bridge, Shangai

(fonte: http://upload.wikimedia.org/wikipedia/commons/thumb/c/c2/Minpu 1st

Bridge.jpg/722px-Minpu 1st Bridge.jpg)

$\mathrm{Na}$ Categoria 3 são inclusas as pontes com distribuição assimétrica dos cabos. Em muitas delas as cargas não são totalmente equilibradas pelo mastro fazendo-se necessária a utilização por dispositivos de ancoragens externos.

A Figura 13 ilustra um dos possíveis arranjos que se encaixam nesta categoria.

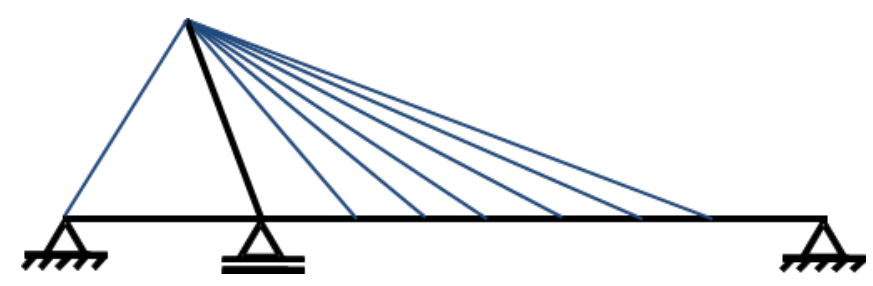

Figura 13 - Ponte estaiada categoria 3 
Este arranjo pode ser visto em diversas pontes estaiadas recentes como a Erasmus Bridge em Rotterdam na Holanda.

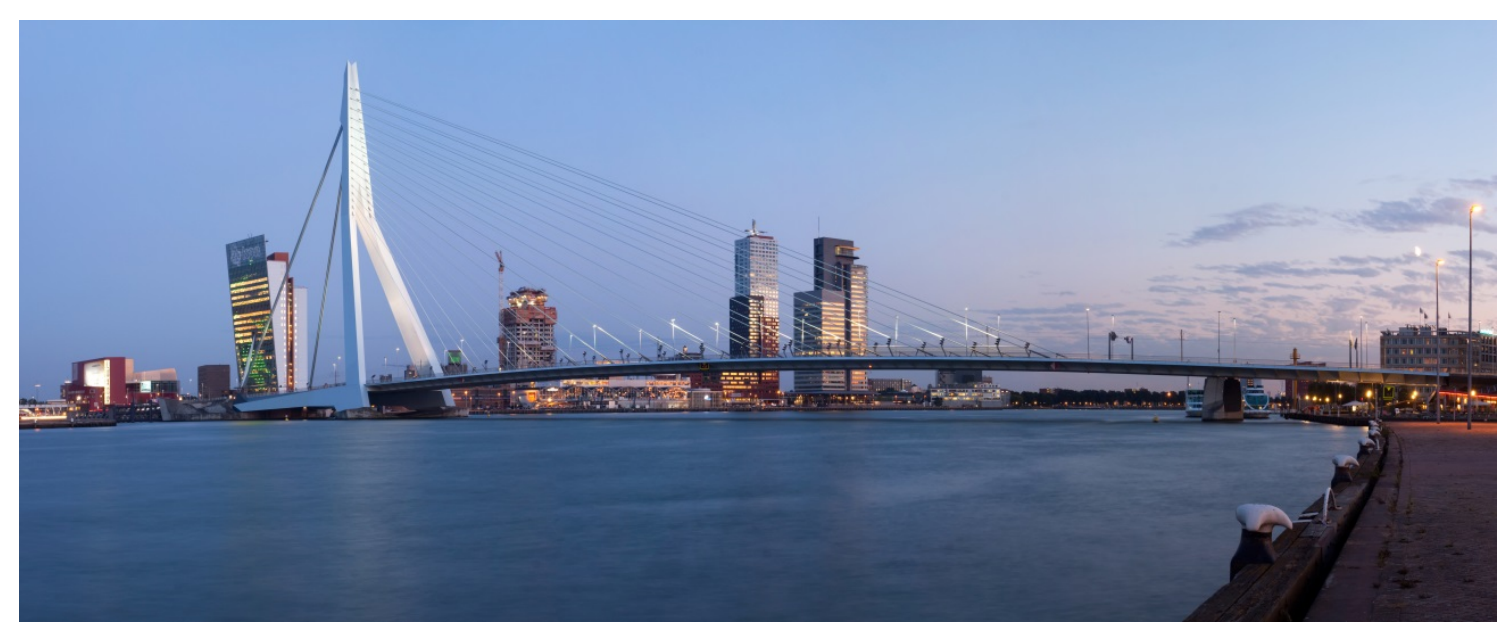

Figura 14 - Erasmus Bridge, Holanda

(fonte: http://openbuildings.com/buildings/erasmusbrug-profile-10044)

Outro aspecto no qual as pontes estaiadas podem ser classificadas é a distribuição transversal dos cabos.

A distribuição em apenas um plano vertical, conforme Figura 15, tem sido amplamente utilizada nas pontes estaiadas.

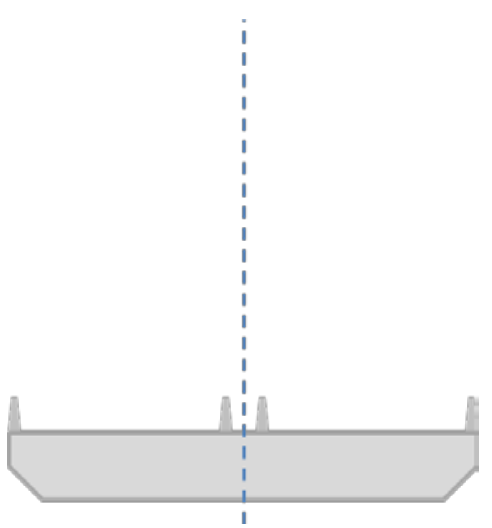

Figura 15 - Plano Vertical Único

Uma das desvantagens deste sistema, é que os cabos suportam apenas os esforços verticais do tabuleiro. Os esforços de torção oriundos do carregamento 
acidental devem ser suportados pelo tabuleiro, exigindo destes, seções mais rígidas a torção, como a seção celular.

Outra desvantagem é que a magnitude dos esforços nas zonas de ancoragem dos cabos é relativamente alta, acarretando aumento o custo deste detalhe de projeto.

Outro arranjo comum para a disposição transversal dos cabos é a utilização de dois ou mais planos verticais, ilustrado na Figura 16. Seguindo a linha das pontes suspensas, onde o tabuleiro é suportado pelas extremidades, é possível se trabalhar com peças mais esbeltas já que estes são solicitados principalmente à flexão.
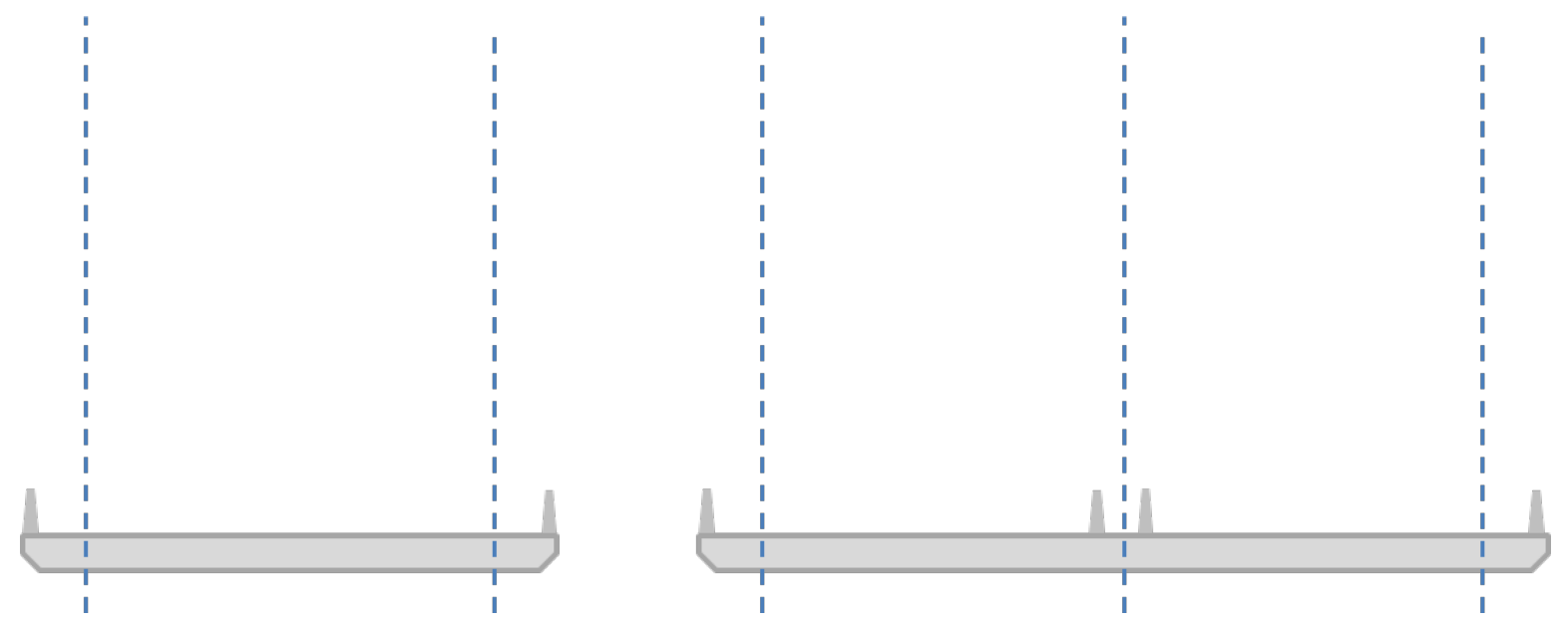

Figura 16 - Dois ou mais Planos Verticais

A desvantagem deste sistema é o custo maior com a elevação de dois ou mais mastros e um maior número de cabos.

Outro sistema muito utilizado são os planos inclinados, ver Figura 17, que tem como vantagem exigir apenas um no caso da utilização de dois planos de cabo. Uma desvantagem é que para dar gabarito para o tráfego uma área do tabuleiro é perdida em função da inclinação dos cabos na direção da via. 


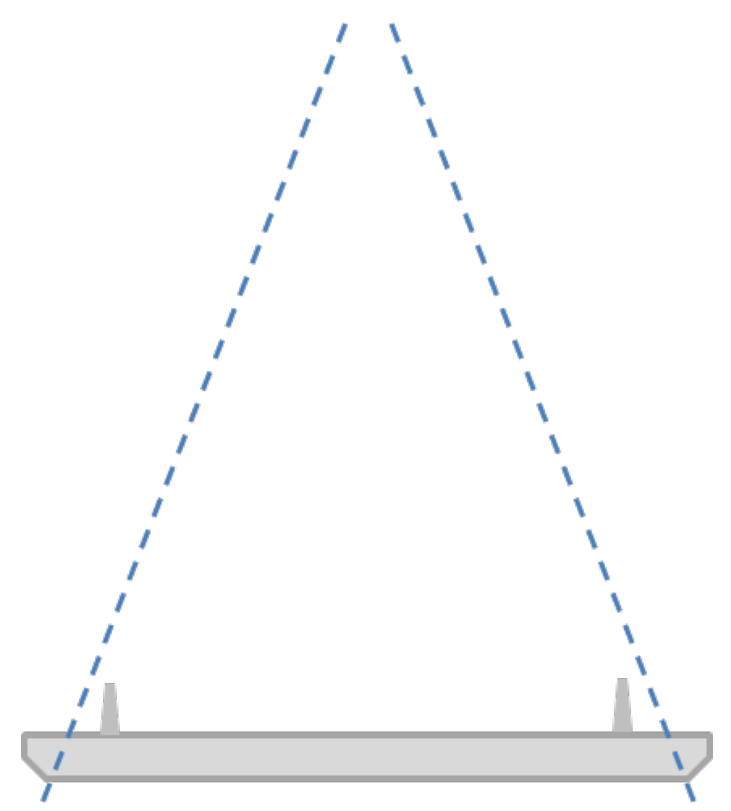

Figura 17 - Planos Inclinados

Nesse sistema também deve-se dar atenção aos esforços de compressão que surgem no sentido transversal do tabuleiro.

Por último classificamos as pontes segundo a distribuição longitudinal dos cabos. Troitsky (1988) classificou a distribuição longitudinal dos cabos em três tipos, harpa, leque e radial, ver Figura 18.
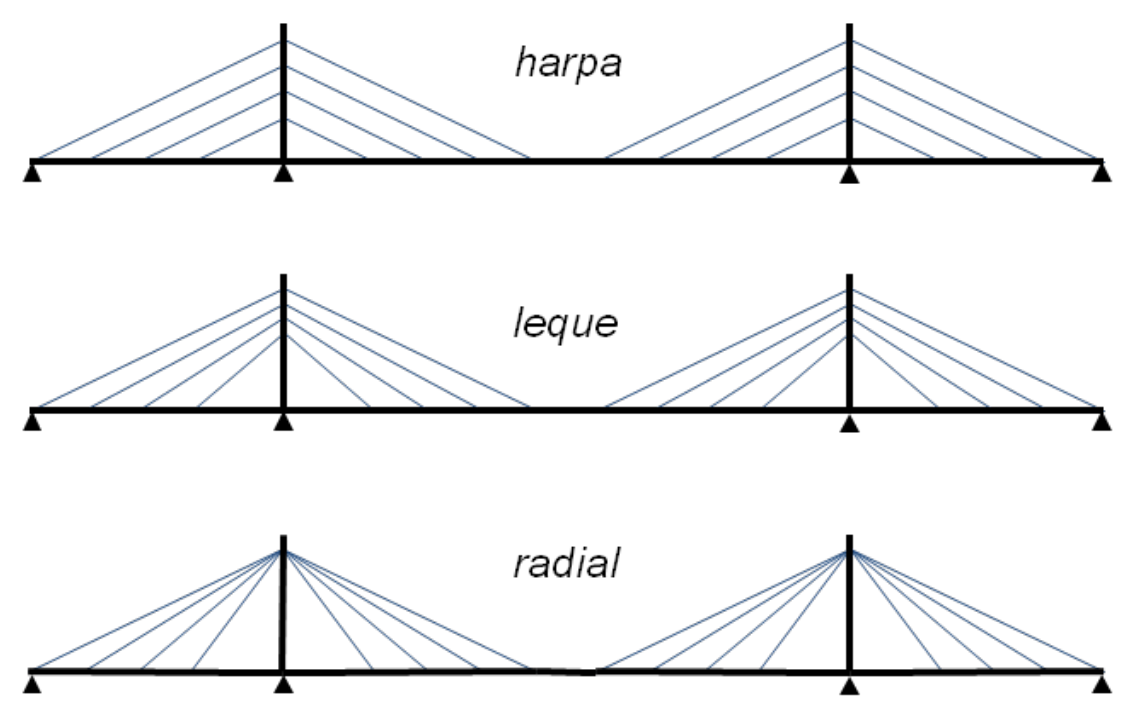

Figura 18 - Distribuição Longitudinal do cabos 
As vantagens e desvantagens de cada um dos modelos mostrados na Figura 18 foi descrita por Troitsky (1988) e estão resumidas na Tabela 1.

Tabela 1 - Vantagens e desvantagens dos arranjos mais comuns dos estais

\begin{tabular}{|c|c|c|}
\hline Sistema & Vantagens & Desvantagens \\
\hline Radial & $\begin{array}{c}\text { Redução da componente axial do cabo } \\
\text { no tabuleiro; os estais carregam o } \\
\text { máximo do peso próprio da estrutura; } \\
\text { redução relativa da quantidade de aço. }\end{array}$ & $\begin{array}{c}\text { Problemas de ligação na região onde } \\
\text { os estais convergem na torre. }\end{array}$ \\
\hline Harpa & $\begin{array}{c}\text { Aumenta a rigidez do vão principal, } \\
\text { Baixa tensão nos cabos. }\end{array}$ & $\begin{array}{c}\text { Gera momento fletor na torre } \\
\text { aumentando a instabilidade da } \\
\text { mesma. }\end{array}$ \\
\hline Leque & $\begin{array}{c}\text { Modificação do sistema em harpa. É um } \\
\text { sistema intermediário que reduz alguns } \\
\text { problemas de ambos os arranjos } \\
\text { anteriores. }\end{array}$ & - \\
\hline
\end{tabular}




\section{MODELAGEM DO CABO}

De acordo com Irvine (1992), datam do início do Século XVII os estudos de Beeckman que atribuíam a forma parabólica a um cabo suspenso sobre atuação de um carregamento distribuído.

A forma catenária foi demonstrada quase que simultaneamente por Leibnitz e Huygens e pelos irmãos Bernoulli. Os irmãos Bernoulli ainda na mesma época contribuíram com a equação diferencial de equilíbrio de um elemento de corrente deformável ao incorporar a Lei de Hooke na formulação.

\subsection{SUSPENSÃO CATENÁRIA}

A curva desenvolvida por um cabo inextensível suspenso vinculado a dois apoios fixos nivelados, pontos $A$ e $B$, sob a atuação de uma carga distribuída é conhecida como catenária, ilustrada na Figura 19, onde $l$ é distância entre os apoios.

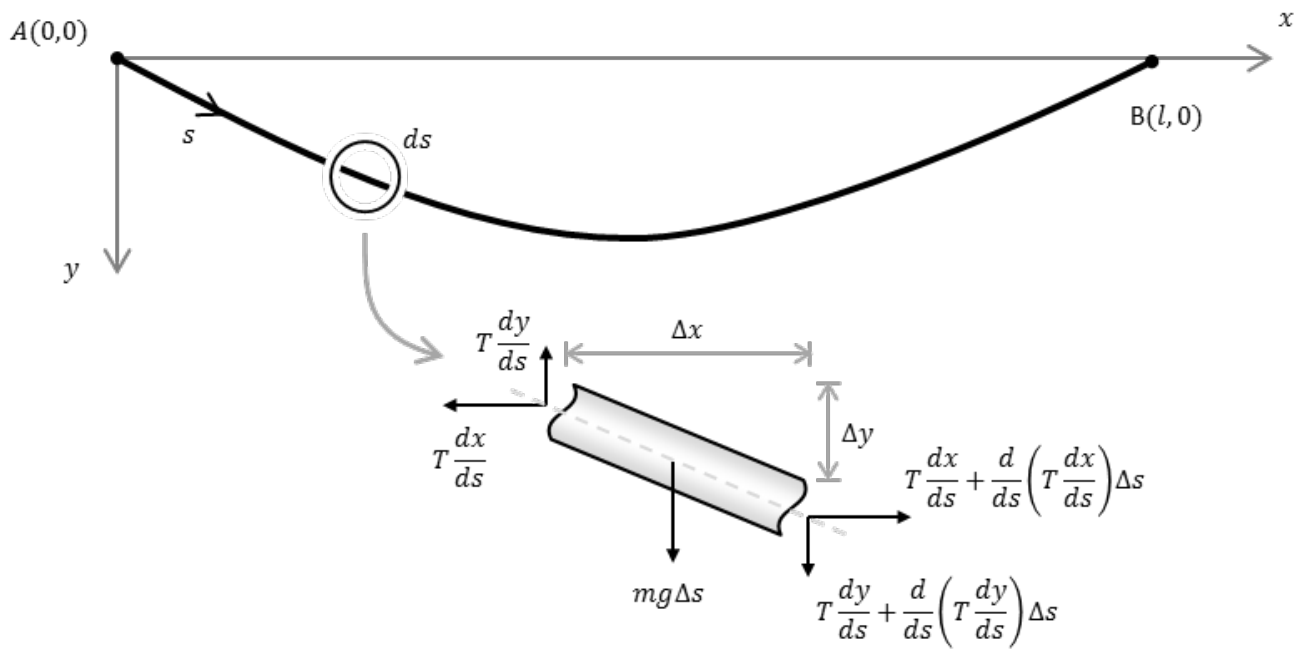

Figura 19 - Suspensão Catenária

Considerando o diagrama de corpo livre do elemento infinitesimal de cabo de comprimento $d s$, ao longo da variável curvilínea $s$ ao longo do cabo, mostrado na Figura 19, onde $T$ é força de tração no cabo e $m g$ é o peso próprio por unidade de 
comprimento, o equilíbrio das forças nas direções $x$ e $y$ é expresso respectivamente pelas equações (1) e (2):

$$
\begin{gathered}
\frac{d}{d s}\left(T \frac{d x}{d s}\right)=0 \\
\frac{d}{d s}\left(T \frac{d y}{d s}\right)=-m g
\end{gathered}
$$

Integrando a equação (1) obtém-se:

$$
T \frac{d x}{d s}=H
$$

Onde $H$ é então a componente horizontal da força $\mathrm{T}$, constante ao longo do cabo desde que não haja carregamento no sentido longitudinal do cabo, que levado na equação (2), resulta em:

$$
H \frac{d^{2} y}{d x^{2}}=-m g \frac{d s}{d x}
$$

Tendo em vista a relação trigonométrica,

$$
\cos ^{2} \theta+\sin ^{2} \theta=\left(\frac{d x}{d s}\right)^{2}+\left(\frac{d y}{d s}\right)^{2}=1
$$

obtemos a equação diferencial do cabo,

$$
H \frac{d^{2} y}{d x^{2}}=-m g \sqrt{1+\left(\frac{d y}{d x}\right)^{2}}
$$

cuja solução é então expressa pela equação (7).

$$
y=\frac{H}{m g}\left\{\cosh \left(\frac{m g l}{2 H}\right)-\cosh \frac{m g}{H}\left(\frac{l}{2}-x\right)\right\}
$$


Onde y é a ordenada do cabo segundo o sistema de eixos ilustrados na Figura 19 e $l$ o comprimento do vão entre os apoios.

\subsection{SUSPENSÃO PARABÓLICA}

Apesar da formulação parabólica, de mais fácil manipulação algébrica para representar a curvatura do cabo suspenso, ter sido contestada, percebeu-se que o erro cometido é muito pequeno em relação à suspensão catenária, quando a relação entre a flecha e o vão é pequena. Assim, a forma parabólica tem sido muito utilizada para evitar a exaustiva manipulação de equações hiperbólicas e diminuir tempo de processamento em ferramentas computacionais.

Para obter a equação da parábola para o cabo, parte-se da equação (6) considerando que o termo $\left(\frac{d y}{d x}\right)^{2}$ tende a zero quando a flecha é pequena e obtemos:

$$
H \frac{d^{2} y}{d x^{2}}=-m g
$$

Que, do ponto de vista da equação (4), pode-se dizer que a intensidade do carregamento do peso próprio do cabo por unidade do comprimento do vão não varia, ou seja:

$$
\frac{d s}{d x} \cong 1
$$

A solução da equação (8), fica expressa por:

$$
y=\frac{m g l}{2 H} x\left(1-\frac{x}{l}\right)
$$

Para facilitar a comparação entre os resultados obtidos com as duas formulações as equações (7) e (10) devem ser expressas de forma paramétrica e com a origem dos eixos a uma distância $a=H / m g$ abaixo do ponto médio do cabo conforme ilustrado na Figura 20 onde $f$ é a flecha desenvolvida pelo cabo no ponto $x=l / 2$. Este comparativo foi apresentado por Poldony, et al. (1974). 


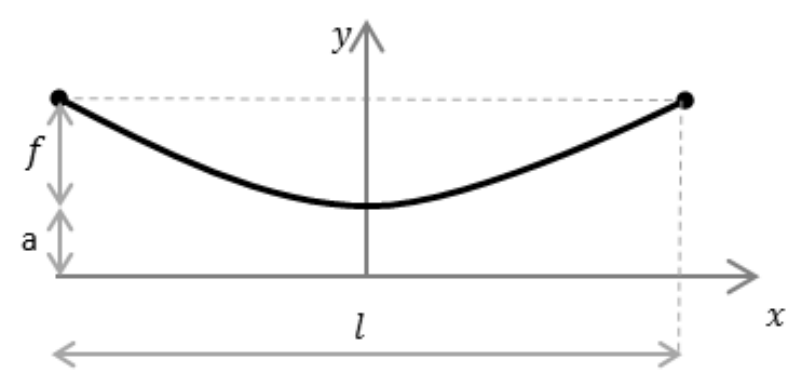

Figura 20 - Sistema de eixos para parametrização das equações

Para a suspensão catenária tem-se o parâmetro,

$$
c=\frac{b}{2}\left(\cosh \frac{1}{2 a}-1\right)
$$

e para suspensão parabólica, o parâmetro correspondente,

$$
c=\frac{1}{4 b}
$$

onde, $b=2 a / l$ e $c=f / l$.

O gráfico da Figura 21 ilustra os resultados obtidos com as duas formulações onde se observa uma diferença muito pequena quando a relação entre a flecha e o vão $c$, é menor que 0,15 para um cabo suspenso com os dois apoios nivelados. 


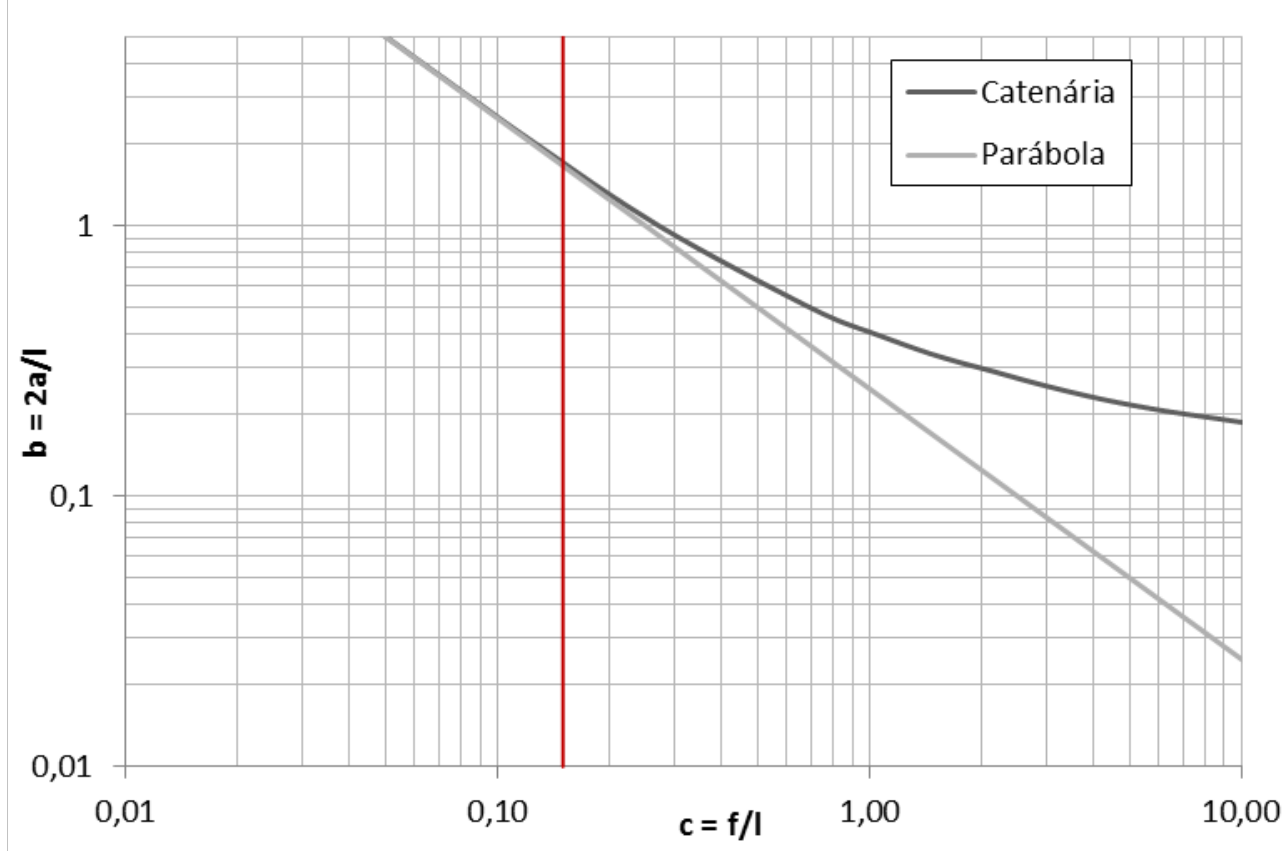

Figura 21 - Gráfico Parábola vs. Catenária

Para um cabo inclinado Podolny, et al, 1976, comparou a diferença entre a suspensão catenária e parabólica em função do comprimento desenvolvido pelo cabo.

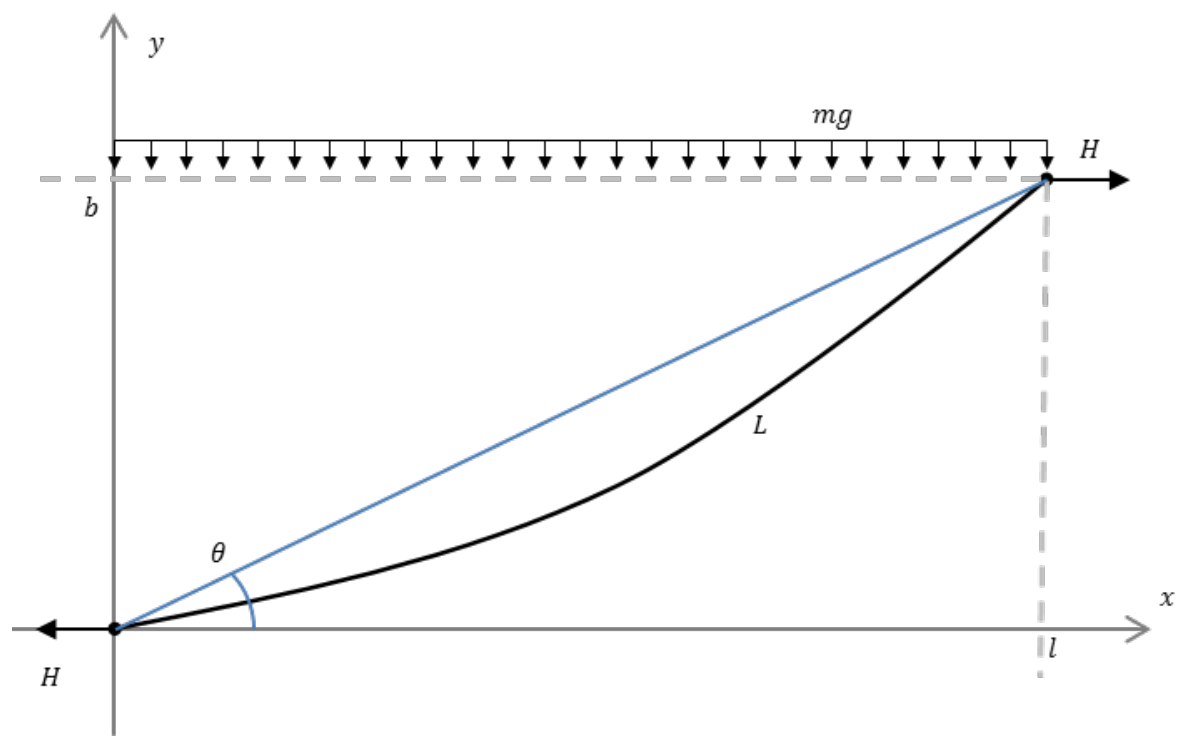

Figura 22 - Cabo Inclinado

Para a catenária o comprimento desenvolvido é dado por, 


$$
L^{2}=h^{2}+4\left(\frac{H}{m g}\right)^{2} \sinh ^{2} \frac{m g l}{2 H}
$$

e para a parábola tem-se,

$$
L=\frac{1}{\cos \theta}\left[1+\frac{8}{3}\left(\frac{m g l^{2}}{8 H} \cos ^{2} \theta\right)^{2}\right]
$$

onde $\theta$ é o ângulo entre a reta formada pelos dois pontos de suspensão do cabo e o plano horizontal $x$.

A Tabela 2 apresenta os resultados onde é variada a intensidade da força horizontal $H$ do cabo nas equações (13) e (14) com valores próximos aos adotados por Podolny, et al, para $m g=4,2 \mathrm{kN} / \mathrm{m}, l=100 \mathrm{~m}, \theta=40^{\circ}$, situação típica de ponte estaiada segundo o mesmo. Observa-se que a diferença ao se usar a parábola para representar o cabo em relação a catenária diminui quando a força horizontal $H$ aumenta.

Tabela 2 - Variação do comprimento total do cabo em função da intensidade da força horizontal

\begin{tabular}{|c|c|c|c|c|}
\hline $\mathbf{H}(\mathbf{k N})$ & $\mathbf{L}_{\mathbf{c}}(\mathbf{m})$ & $\mathbf{L}_{\mathbf{p}}(\mathbf{m})$ & $\mathbf{\Delta} \mathbf{L}=\mathbf{L}_{\mathbf{c}}-\mathbf{L}_{\mathbf{p}}$ & $\mathbf{\Delta} \mathbf{L} / \mathbf{L}_{\mathbf{c}} \%$ \\
\hline 250 & 112,18 & 111,76 & 0,42 & $0,38 \%$ \\
\hline 500 & 102,97 & 102,94 & 0,03 & $0,03 \%$ \\
\hline 750 & 101,31 & 101,31 & 0,01 & $0,01 \%$ \\
\hline 1000 & 100,74 & 100,74 & 0,00 & $0,00 \%$ \\
\hline 1250 & 100,47 & 100,47 & 0,00 & $0,00 \%$ \\
\hline
\end{tabular}

A Figura 23 mostra a influência da variação do ângulo $\theta$ na diferença computada entre as duas formulações. 


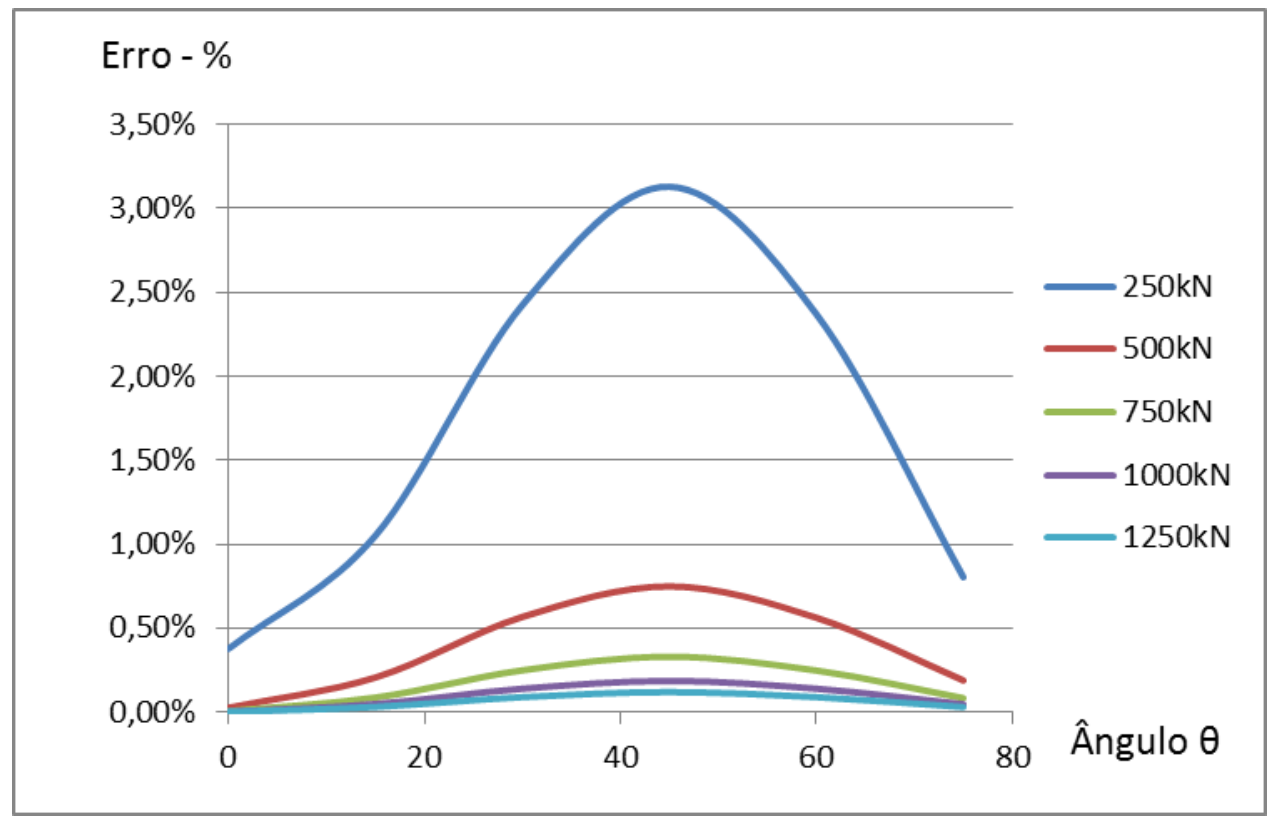

Figura 23 - Diferença entre catenária e parábola

Observa-se que a diferença também é pequena para os cabos inclinados quando o nível de tensionamento no cabo é alto, ou seja, quando a relação entre a flecha e o é vão pequena.

\subsection{MÓDULO DE DISCHINGER}

Para resolver o problema do cabo tracionado, Dischinger foi o primeiro a apresentar trabalhos na área. Porém a forma mais conhecida é o Módulo de Elasticidade Equivalente, $E_{e q, D}$, apresentado por Enrst (1965), que expresso em termos da tração no cabo fica dado como:

$$
E_{e, q D}=\frac{E}{1+\frac{\left(g_{y} l\right)^{2} E}{12 T^{3}}}
$$

Onde $E$ é o módulo de elasticidade efetivo do cabo, $T$ a força de tração no cabo e $g_{y}$ a componente perpendicular ao cabo de $\mathrm{mg}$. 
Para obter o módulo de Dischinger, deve-se considerar como hipótese que a curva do cabo assume a forma de uma parábola, desconsiderando a componente paralela ao cabo do peso próprio.

\subsection{MÓDULO DE DISCHINGER MODIFICADO}

De acordo com Hajdin (1998) o erro ao utilizar a parábola como forma do cabo não passa de $0,05 \%$ do cabo em serviço. Porém, verificou-se que ao desconsiderar a componente tangencial do peso próprio a diferença pode chegar a $20 \%$ para o cabo parcialmente tracionado e $8 \%$ totalmente em serviço.

Para obtenção do módulo de Hajdin assume-se o sistema de eixos paralelo ao eixo entre apoios do cabo, apresentado na Figura 24, onde $f$ é a flecha no meio do vão, $x=l / 2$.

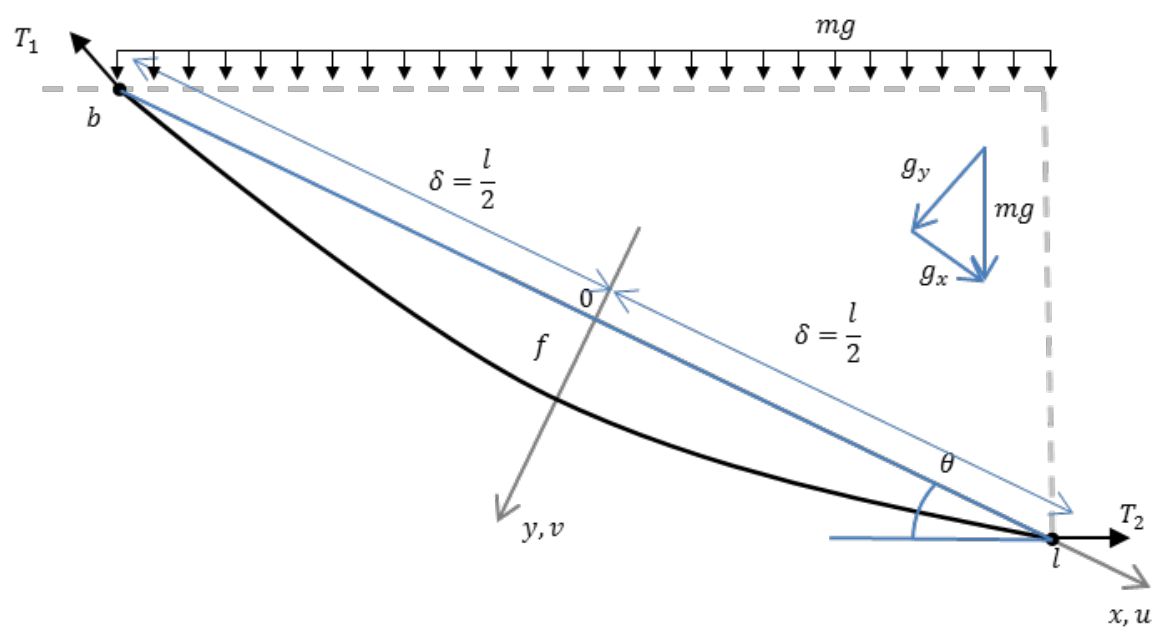

Figura 24 - Diagrama de corpo livre para obtenção do Módulo de Hajdin

Neste sistema a seguinte equação da parábola representa a geometria do cabo, Hajdin (1998):

$$
v=f\left[1-\left(\frac{x}{8}\right)^{2}\right]
$$

Onde a derivada em relação a $x$ fica expressa por: 


$$
\frac{d v}{d x}=-2 f \frac{x}{\theta^{2}}
$$

Considerando o diagrama de corpo livre apresentado na Figura 25, e resolvendo o equilíbrio de momentos da metade do cabo, equação (18), obtemos a equação (19).

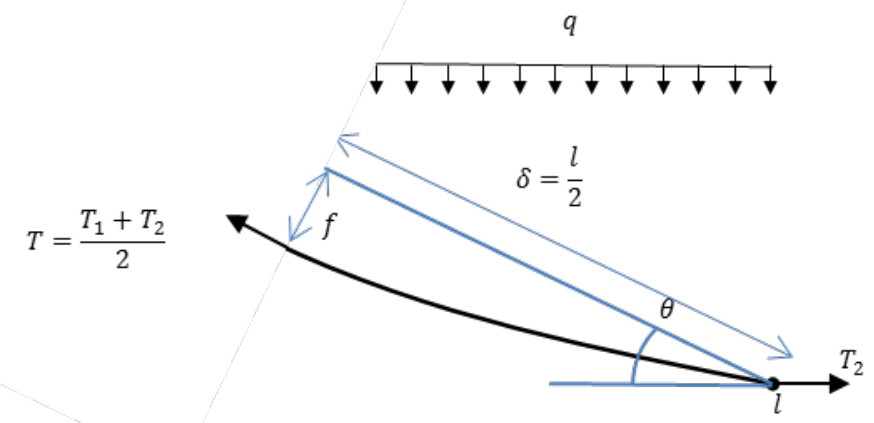

Figura 25 - Diagrama de corpo livre da metade do cabo

$$
\begin{gathered}
T f-g_{y} \frac{\delta^{2}}{2}-\int_{0}^{\delta} g_{x} v(x) d x=0 \\
f=\frac{3}{2} \frac{g_{y} \delta^{2}}{3 T-2 g_{x} \delta}
\end{gathered}
$$

Substituindo a equação (19) na derivada da parábola em relação a $x$, equação (17), obtemos:

$$
\frac{d v}{d x}=\frac{3 g_{y} x}{3 T-2 g_{x} \delta}
$$

Considerando o elemento infinitesimal em uma determinada posição de comprimento $d x$, que sob ação dos esforços de peso próprio e forças nas extremidades sofre um deslocamento $u$ na direção de $x$ e $v$ na direção de $y$, e uma deformação $\epsilon$ assumindo a configuração mostrada na Figura 26. 


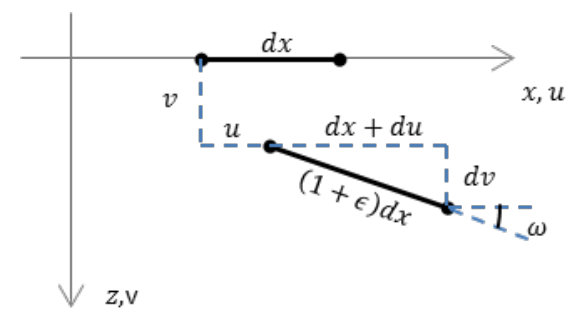

Figura 26 - Deslocamento do elemento infinitesimal do cabo

A partir do mostrado na Figura 26 as equações de compatibilidade (21) e (22) são obtidas.

$$
\begin{gathered}
d x+d u=(1+\epsilon) d x \cos \omega \\
d v=(1+\epsilon) d x \operatorname{sen} \omega
\end{gathered}
$$

No campo dos pequenos deslocamentos, pode-se considerar $\cos \omega=1-\frac{\omega^{2}}{2}$ e $\operatorname{sen} \omega=\omega$, que substituídos nas equações (21) e (22) e desconsiderando os termos de segunda ordem obtem-se:

$$
\epsilon=\frac{d u}{d x}+\frac{1}{2}\left(\frac{d v}{d x}\right)^{2}
$$

Sabendo que a tração no cabo $T$ é igual a

$$
T=A E \epsilon=A E\left[\frac{d u}{d x}+\frac{1}{2}\left(\frac{d v}{d x}\right)^{2}\right]
$$

onde $A$ é área da seção transversal do cabo e $E$ o módulo de elasticidade do cabo, tem-se então:

$$
\frac{d u}{d x}=\frac{T}{E A}-\frac{1}{2}\left(\frac{3 g_{y} x}{3 T-2 g_{x} \delta}\right)^{2}\left(\frac{x}{\delta}\right)^{2}
$$


O alongamento total do cabo $\Delta l$ é obtido a partir da integral da equação (25), ao longo do comprimento $l$, distância total entre os dois apoios do cabo, conforme Figura 24.

$$
\Delta l=\int_{-\delta}^{\delta} \frac{d u}{d x} d x=\frac{2 T \delta}{E A}-\left(\frac{3 g_{y}}{3 T-2 g_{x} \delta}\right)^{2} \frac{\delta^{3}}{3}
$$

Substituindo $\delta=l / 2$ na equação (26), tem-se a deformação do cabo em função de uma tração $T$.

$$
\frac{\Delta l}{l}=\frac{T}{E A}-\frac{1}{24}\left(\frac{3 g_{y}}{3 T-2 g_{x} l}\right)^{2}
$$

Para uma força $\bar{T}$ obtem-se de forma análoga um alongamento $\overline{\Delta l}$ e uma deformação expressa por:

$$
\frac{\overline{\Delta l}}{l}=\frac{\bar{T}}{E A}-\frac{1}{24}\left(\frac{3 g_{z}}{3 \bar{T}-2 g_{x} \delta}\right)^{2}
$$

Para um acréscimo pequeno, a deformação de um elemento retilíneo entre os apoios é aproximadamente igual a deformação do cabo. Sendo assim, pode-se considerar que a deformação axial de um elemento fictício retilíneo entre os dois apoios, $\overline{\Delta \epsilon}$, é dada por:

$$
\overline{\Delta \epsilon}=\frac{\overline{\Delta l}}{l}-\frac{\Delta l}{l}=\frac{\bar{T}-T}{E A}-\frac{1}{24}\left\{\left(\frac{3 g_{z}}{3 \bar{T}-2 g_{x} \delta}\right)^{2}-\left(\frac{3 g_{z}}{3 T-2 g_{x} \delta}\right)^{2}\right\}
$$

Da Lei de Hooke obtem-se:

$$
\overline{\Delta \epsilon}=\frac{\Delta \sigma}{E_{e q}}=\frac{1}{E_{e q}} \frac{\bar{T}-T}{A}
$$

Onde $E_{e q}$ é o módulo de elasticidade equivalente do elemento fictício de cabo.

Levando a equação (30) na equação (29), após manipulações algébricas, obtem-se a formulação proposta por Hajdn (2000) 


$$
E_{e q}=\frac{E}{1+\frac{E A\left(g_{y} l\right)^{2}}{24} \frac{\left(\bar{T}+T-\frac{2}{3} g_{x} l\right)}{\left[\bar{T} T-\frac{g_{x} l}{3}(\bar{T}+T)+\left(\frac{g_{x} l}{3}\right)^{2}\right]^{2}}}
$$

Fazendo $T=\bar{T}$ obtem-se,

$$
E_{e q}=\frac{E}{1+\frac{E A\left(g_{y} l\right)^{2}}{24} \frac{\left(2 T-\frac{2}{3} g_{x} l\right)}{\left[T^{2}-\frac{2 g_{x} l}{3} T+\left(\frac{g_{x} l}{3}\right)^{2}\right]^{2}}}
$$

Para obter a formulação proposta por Dischinger basta considerar que a componente tangencial do peso próprio do cabo seja nula, $g_{x}=0$. Isso faz com que a equação (32) assuma a seguinte forma:

$$
E_{\text {eq,Dishinger }}=\frac{E}{1+\frac{\left(g_{y} l\right)^{2}}{12 T^{3}} E}
$$




\section{ANÁliSE NÃO LINEAR GEOMÉtRICA BASEADA NA FORMULAÇÃO POSICIONAL DO MÉTODO DOS ELEMENTOS FINITOS}

O programa desenvolvido tem como princípio básico buscar a situação de equilíbrio da estrutura na posição deslocada, utilizando uma lei constitutiva não linear para o elemento de treliça, partindo do princípio da mínima energia potencial total.

A medida de deformação escolhida para formulação da lei constitutiva utilizada deve ser uma medida de deformação objetiva, pois não gera deformações para movimento de corpo rígido. Isto é de fundamental importância para uma formulação não linear geometricamente exata.

Nestes termos trabalha-se com a Medida de Deformação de Green, extraída diretamente do tensor de alongamento de Cauchy-Green, $C$,

$$
\varepsilon_{G}=1 / 2(C-I)
$$

que para deformações uniaxiais é definida por:

$$
\varepsilon_{G}=\frac{1}{2} \frac{\boldsymbol{L}^{2}-\boldsymbol{L}_{0}^{2}}{\boldsymbol{L}_{0}^{2}}
$$

Onde $\boldsymbol{L}$ é o comprimento atual do elemento e $\boldsymbol{L}_{0}$ o comprimento inicial do elemento, conforme ilustrado na Figura 29.

A deformação de Green coincide com a deformação de engenharia em níveis baixos de deformação, conforme ilustra a Figura 27, mesmo que no problema ocorram grandes deslocamentos. A diferença percentual é apresentada na Figura 28. 


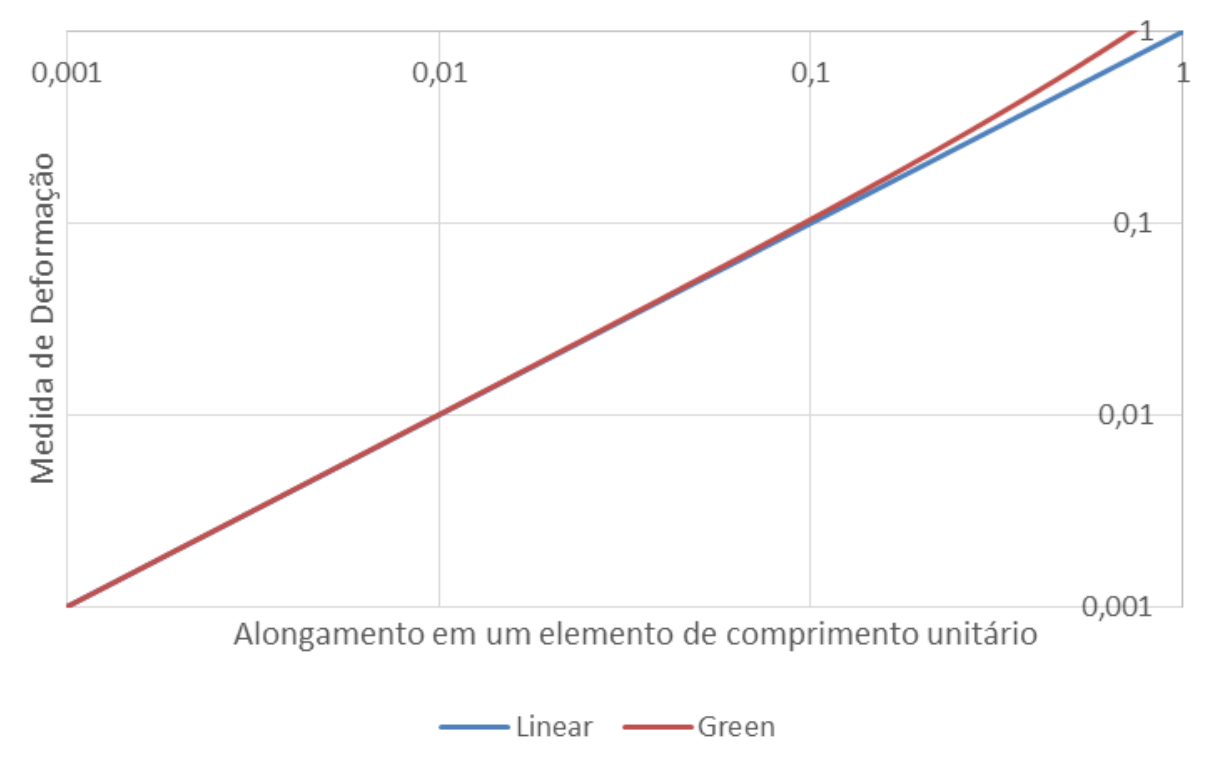

Figura 27 - Deformação de Green x Deformação Linear

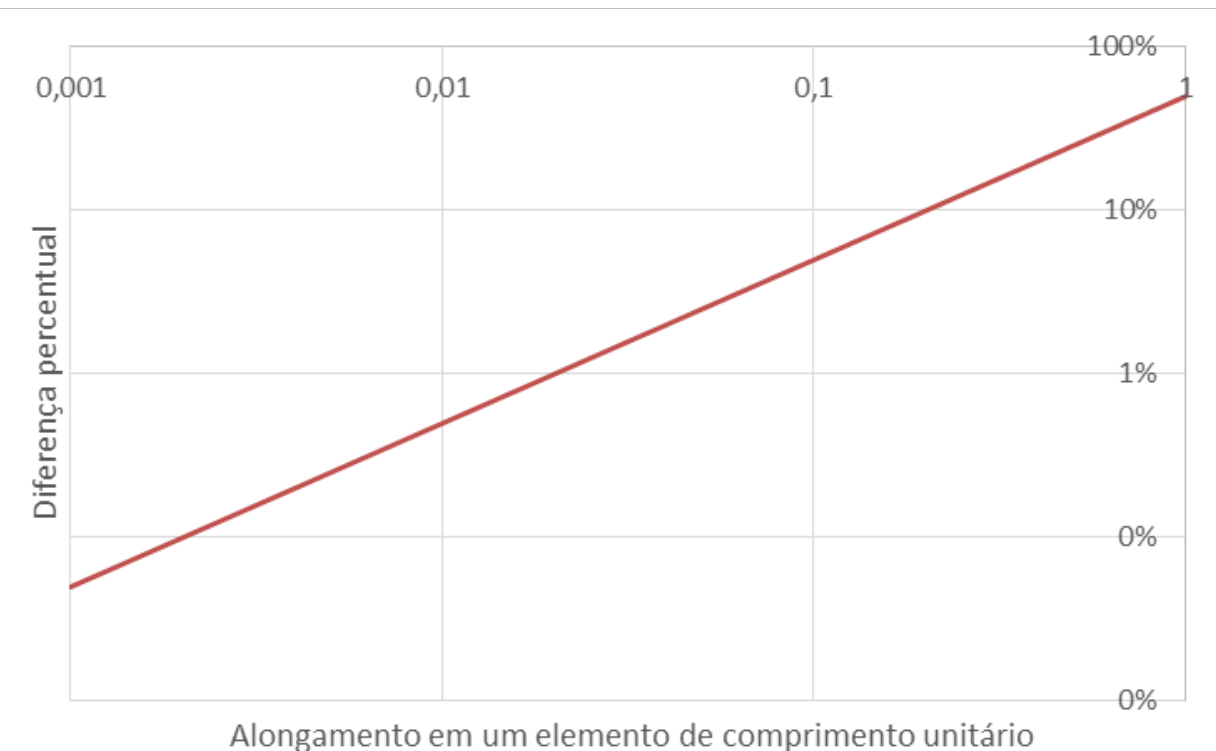

Figura 28 - Diferença \% entre Green e deformação Linear

Aplicando a Lei de Hooke integral com a deformação de Green, ou seja substituindo a deformação linear pela deformação de Green para. Assim é obtida a Lei constitutiva de Saint-Venant-Kirchhoff, a energia específica de deformação $u_{e}$ em termos deformação de Green, representada na Equação (36), onde $E$ é módulo de elasticidade do material. 


$$
u_{e}=\frac{E \cdot \varepsilon_{G}^{2}}{2}
$$

\subsection{FORMULAÇÃO NÃO LINEAR}

Partindo do princípio da mínima energia potencial total tem-se,

$$
\Pi=U_{e}+P
$$

onde $U_{e}$ é a energia total de deformação do sistema e $P$ é a energia potencial das forças externas.

A partir da primeira derivada da equação (37) em relação à posição $Y$ (atual), ver Figura 29, em um sistema de forças conservativas é obtida a equação (38).

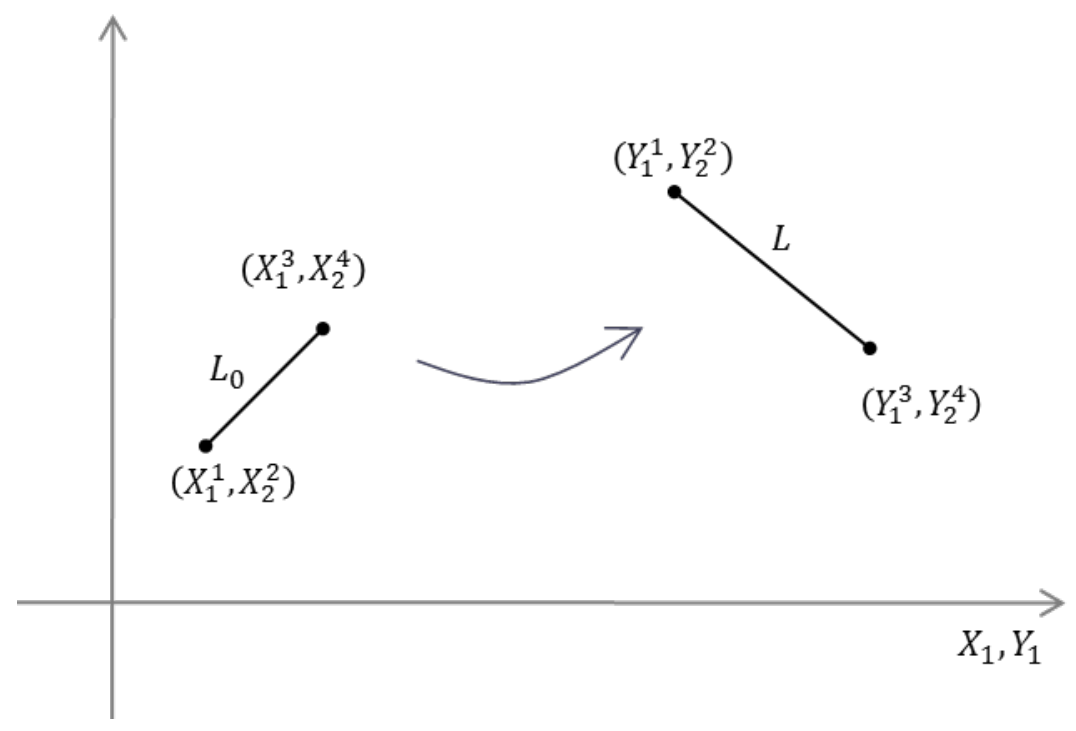

Figura 29 - Configuração indeformada $\mathbf{X}$ e atual $\mathbf{Y}$ do elemento de treliça

$$
\frac{\partial \Pi}{\partial \boldsymbol{Y}}=0=\frac{\partial U_{e}}{\partial \boldsymbol{Y}}+P_{i}
$$


Sabendo que o conjugado energético de posição, quando se considera a energia complementar, é força, a equação (38) descreve o equilíbrio das forças internas $\frac{\partial U_{e}}{\partial Y}$ com as forças externas $P_{i}$.

Para resolver o problema deve-se encontrar a posição deformada da estrutura que satisfaça a condição de equilíbrio dada na equação (39),

$$
\frac{\partial U_{e}}{\partial \boldsymbol{Y}}-P_{i}=0
$$

É utilizada a técnica de solução de sistemas não lineares de Newton-Raphson para encontrar a posição final de equilíbrio da estrutura.

\section{Matriz Hessiana local}

A matriz hessiana local de cada elemento de treliça é obtida através da segunda derivada da energia de deformação da barra em função posição final do elemento, ou seja, a derivada das forças internas do elemento de barra.

A energia de deformação da barra é obtida através da integral da energia específica de deformação, dada na equação (36), no volume inicial da barra.

Assumindo elementos de barra simples uniaxiais tem-se:

$$
U_{e}=\int_{V_{0}} u_{e} d V_{0}
$$

Onde $V_{0}$ é o volume incial da barra, o qual é constante e igual ao produto da área, $A$, pelo comprimento inicial da barra $l_{0}$.

$$
U_{e}=\frac{E A \boldsymbol{L}_{0}}{2} \varepsilon_{G}^{2}
$$

Onde para os elementos de barra, termos da configuração deformada $\boldsymbol{Y}$, temos a deformação de Green expressa por:

$$
\varepsilon_{G}=\frac{1}{2} \frac{\boldsymbol{L}^{2}-\boldsymbol{L}_{0}^{2}}{\boldsymbol{L}_{0}^{2}}=\frac{1}{2} \frac{\left[\left(\boldsymbol{Y}_{3}-\boldsymbol{Y}_{1}\right)^{2}+\left(\boldsymbol{Y}_{4}-\boldsymbol{Y}_{2}\right)^{2}\right]-\boldsymbol{L}_{0}^{2}}{\boldsymbol{L}_{0}^{2}}
$$


Sabendo que força interna é conjugado energético da posição atual, a partir da (43), obtém-se o vetor de forças internas, na equação (44), representado na Figura 30.:

$$
\begin{gathered}
F=\frac{\partial U_{c}}{\partial \boldsymbol{Y}} \\
F=\frac{E A \varepsilon_{G}}{\boldsymbol{L}_{0}}\left[\begin{array}{l}
\boldsymbol{Y}_{1}-\boldsymbol{Y}_{3} \\
\boldsymbol{Y}_{2}-\boldsymbol{Y}_{4} \\
\boldsymbol{Y}_{3}-\boldsymbol{Y}_{1} \\
\boldsymbol{Y}_{4}-\boldsymbol{Y}_{2}
\end{array}\right]
\end{gathered}
$$

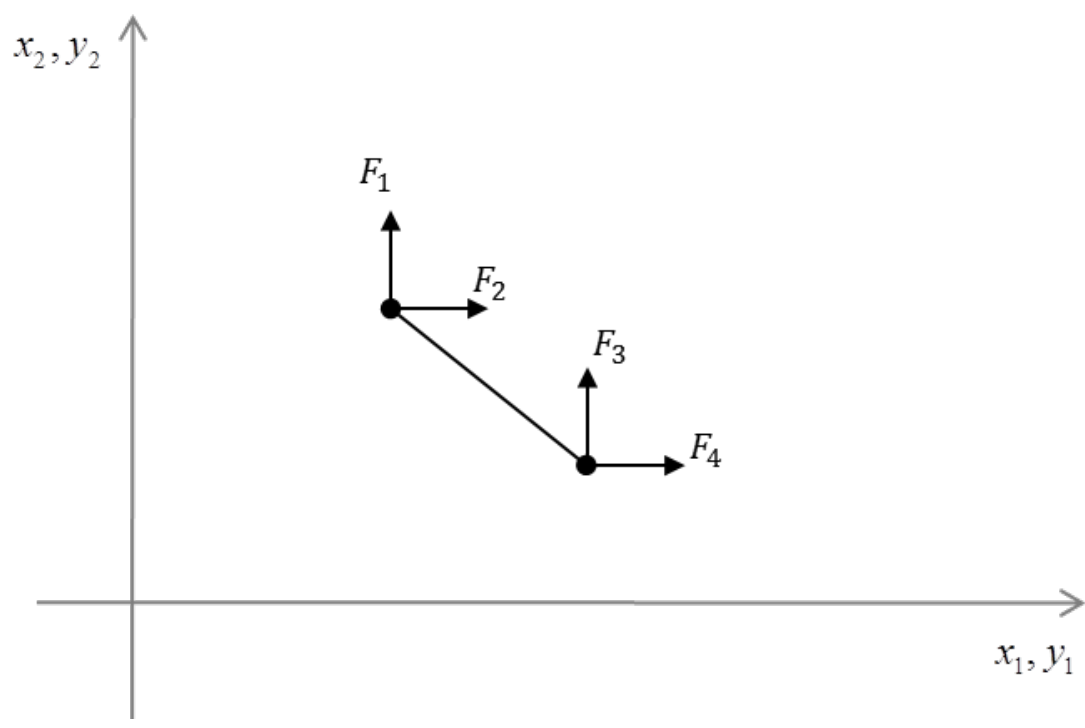

Figura 30 - Forças internas - Graus de Liberdade do Elemento de treliça

Para resolução do sistema não linear apresentado na equação (39) tem-se em uma primeira tentativa que

$$
\frac{\partial U_{e}}{\partial \boldsymbol{Y}}+P_{i}=g_{i}
$$

Onde $g$ é o vetor de desbalanceamento da energia.

Sabendo que para o equilíbrio da forças internas pelas forças externas devese ter $g=0$, efetiva-se a expansão em série de Taylor do termo $g$, e obtemos: 


$$
g_{i}=g_{i}^{0}+\frac{\partial g_{i}}{\partial \boldsymbol{Y}} \Delta \boldsymbol{Y}+\theta_{i}^{2}
$$

Onde $\theta$ são as derivadas de ordem superior desprezadas neste trabalho.

Fazendo $g_{i}=0$, tem-se a Hessiana global dada por

$$
\frac{\partial g_{i}}{\partial \boldsymbol{Y}_{j}}=H_{i j}=\frac{\partial^{2} U_{e}}{\partial \boldsymbol{Y}_{i} \partial \boldsymbol{Y}_{j}}+0=\frac{\partial F}{\partial \boldsymbol{Y}_{j}}
$$

Tomando apenas a primeira derivada das forças internas, já que num sistema de forças conservativas, $\frac{\partial P}{\partial y_{j}}=0$,já que as forças externas não variam com a posição.

Então a matriz hessiana para cada elemento, ou matriz hessiana local fica dada por:

$h_{i, j}=E A\left[\begin{array}{cccc}\left(Y_{3}-Y_{1}\right)^{2}+\varepsilon_{G} \boldsymbol{L}_{0} & \left(Y_{3}-Y_{1}\right)\left(Y_{4}-Y_{2}\right) & -\left(Y_{3}-Y_{1}\right)^{2}-\varepsilon_{G} \boldsymbol{L}_{0} & -\left(Y_{3}-Y_{1}\right)\left(Y_{4}-Y_{2}\right) \\ & \left(Y_{4}-Y_{2}\right)^{2}+\varepsilon_{G} \boldsymbol{L}_{0} & -\left(Y_{3}-Y_{1}\right)\left(Y_{4}-Y_{2}\right) & -\left(Y_{4}-Y_{2}\right)^{2}-\varepsilon_{G} \boldsymbol{L}_{0} \\ \text { simétrica } & \left(Y_{3}-Y_{1}\right)^{2}+\varepsilon_{G} \boldsymbol{L}_{0} & \left(Y_{3}-Y_{1}\right)\left(Y_{4}-Y_{2}\right) \\ & & \left(Y_{4}-Y_{2}\right)^{2}+\varepsilon_{G} \boldsymbol{L}_{0}\end{array}\right]$

A matriz local é somada então na matriz global em seus respectivos graus de liberdade para a resolução do sistema.

Foi desenvolvido um programa em FORTRAN com a estrutura apresentada na Figura 31. 


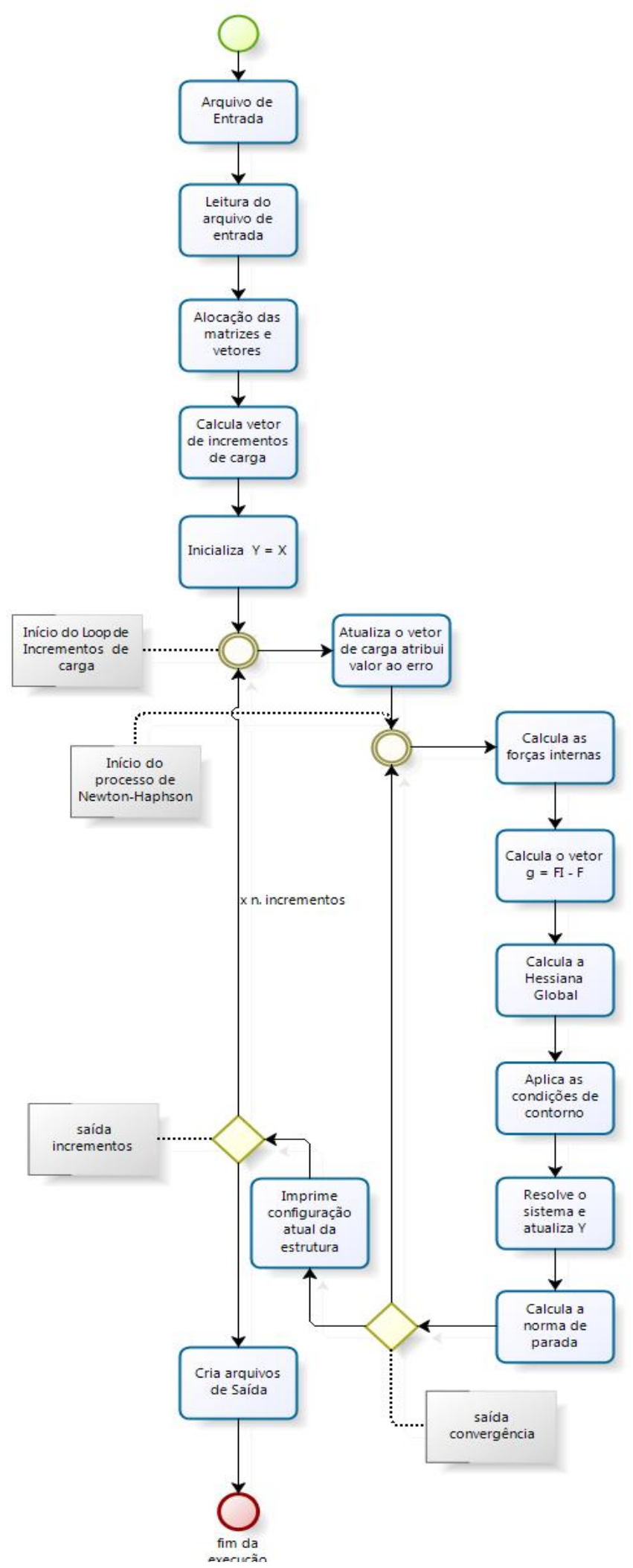

Figura 31 - Fluxograma - Programa para Análise Não Linear Geométrica com a formulação Posicional do Elementos Finitos 


\subsection{VERIFICAÇÕES NUMÉRICAS}

Dois exemplos foram utilizados para a verificação do programa para análise do cabo, o cabo pré-tensionado sob ação apenas de um carregamento distribuído (peso próprio) e o cabo suspenso sob ação da carga distribuída e de uma carga pontual.

\subsection{CABO PRÉ-TENSIONADO}

O problema a seguir foi estudado por Jaymaran (1981) para demonstrar a viabilidade de aplicação dos elementos apresentados no seu trabalho. Os resultados foram anteriormente apresentados por Ozdemir, 1978.

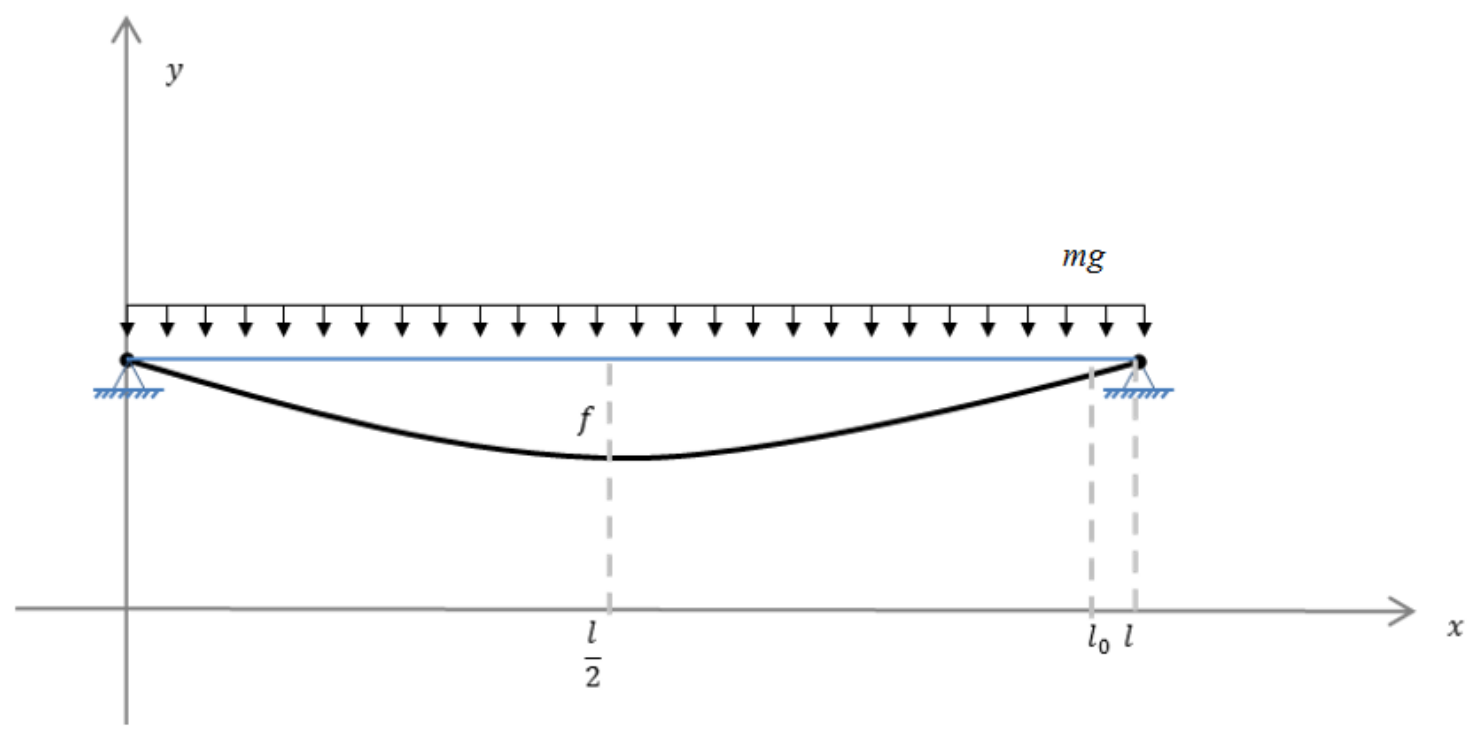

Figura 32 - Cabo pré-tensionado sob ação de carga distribuída

Para modelagem deste exemplo, o cabo foi discretizado em 24 elementos de treliça ao longo da reta que liga os nós de extremidade, conforme a ilustra a Figura 32. Aplicou-se um deslocamento pré-calculado em função do pré-tensionamento desejado. Em seguida a carga do peso próprio do cabo é aplicada nos nós para avaliação da flecha no centro do cabo. 
Foram adotados os seguintes parâmetros para análise:

$$
\begin{gathered}
l_{0}=253,75 \mathrm{~m} \\
l=254 \mathrm{~m} \\
A=4,19 \times 10^{-5} \mathrm{~m}^{2} \\
E=137,89 \mathrm{GPa}
\end{gathered}
$$

A Tabela 3 apresenta os resultados obtidos variando a carga distribuída ao longo do cabo. Os resultados estão comparados com os valores obtidos por Jaymaran (1981).

Tabela 3 - Flechas do cabo pré-tensionado

\begin{tabular}{|c|c|c|c|c|}
\hline & Carga (kN) & Jaymaran & NLG & dif. \% \\
\hline 1 & 3,496 & 3,339 & 3,355 & $0,48 \%$ \\
\hline 2 & 10,487 & 5,949 & 5,954 & $0,09 \%$ \\
\hline 3 & 17,478 & 7,438 & 7,436 & $-0,02 \%$ \\
\hline 4 & 24,470 & 8,536 & 8,528 & $-0,10 \%$ \\
\hline 5 & 31,461 & 9,428 & 9,414 & $-0,15 \%$ \\
\hline
\end{tabular}

Este exemplo também é importante para ilustrar o efeito do enrijecimento do cabo com o aumento da carga, conforme pode ser visto no gráfico da Figura 33, o qual ilustra graficamente os resultados apresentados na Tabela 3. 


\section{Carga $\mathrm{kN} / \mathrm{m}$}

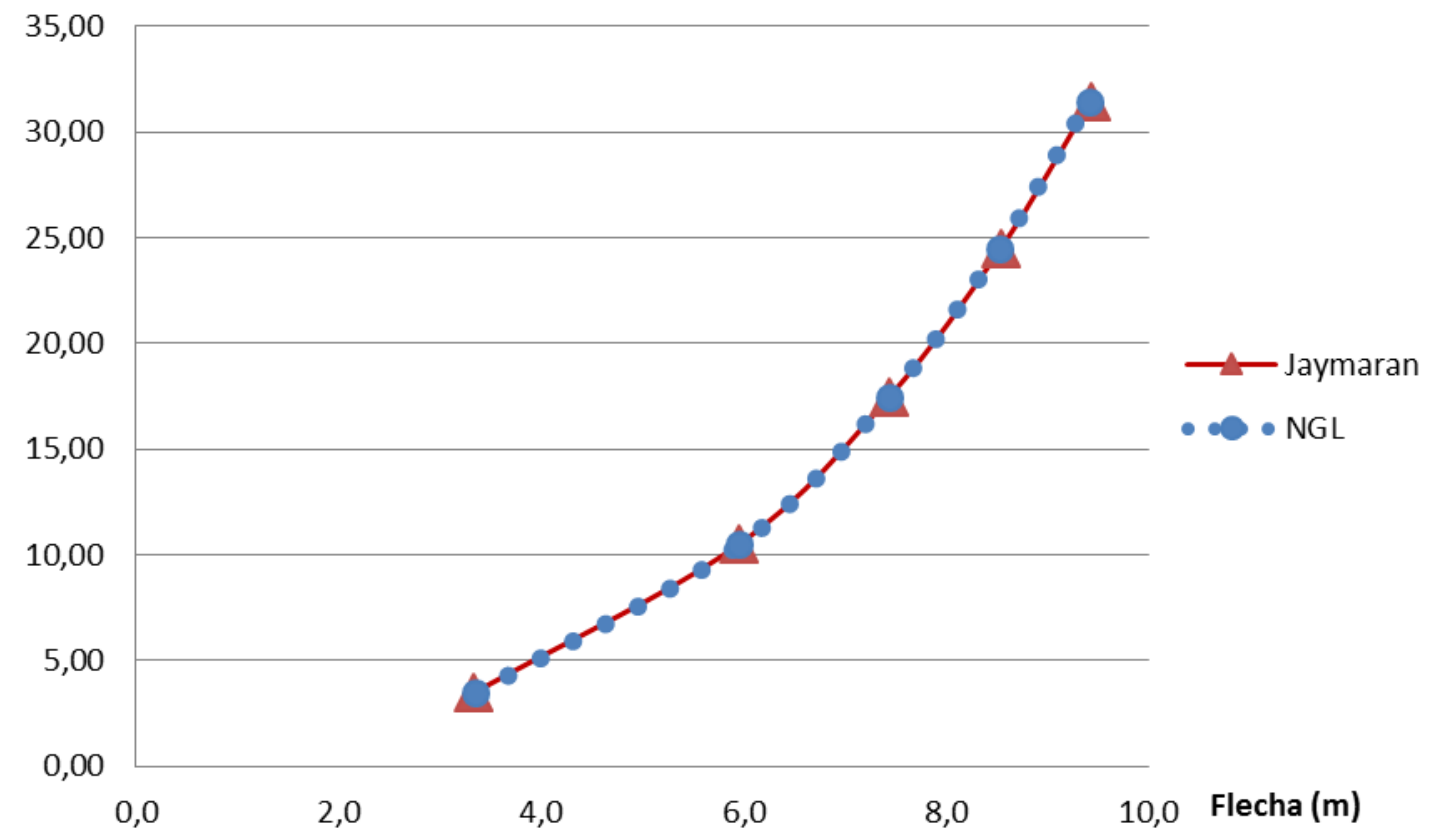

Figura 33 - Deslocamento em função do acréscimo de carga distribuída 


\subsection{CABO SUSPENSO COM CARGA CONCENTRADA}

Neste exemplo, por Jaymaran (1981), o cabo está sujeito apenas ao peso próprio e uma carga concentrada $P$, conforme pode ser visto na Figura 34. A discretização dos elementos é feita a partir da catenária assumindo que é a configuração inicial do cabo imediatamente antes da deformação elástica.

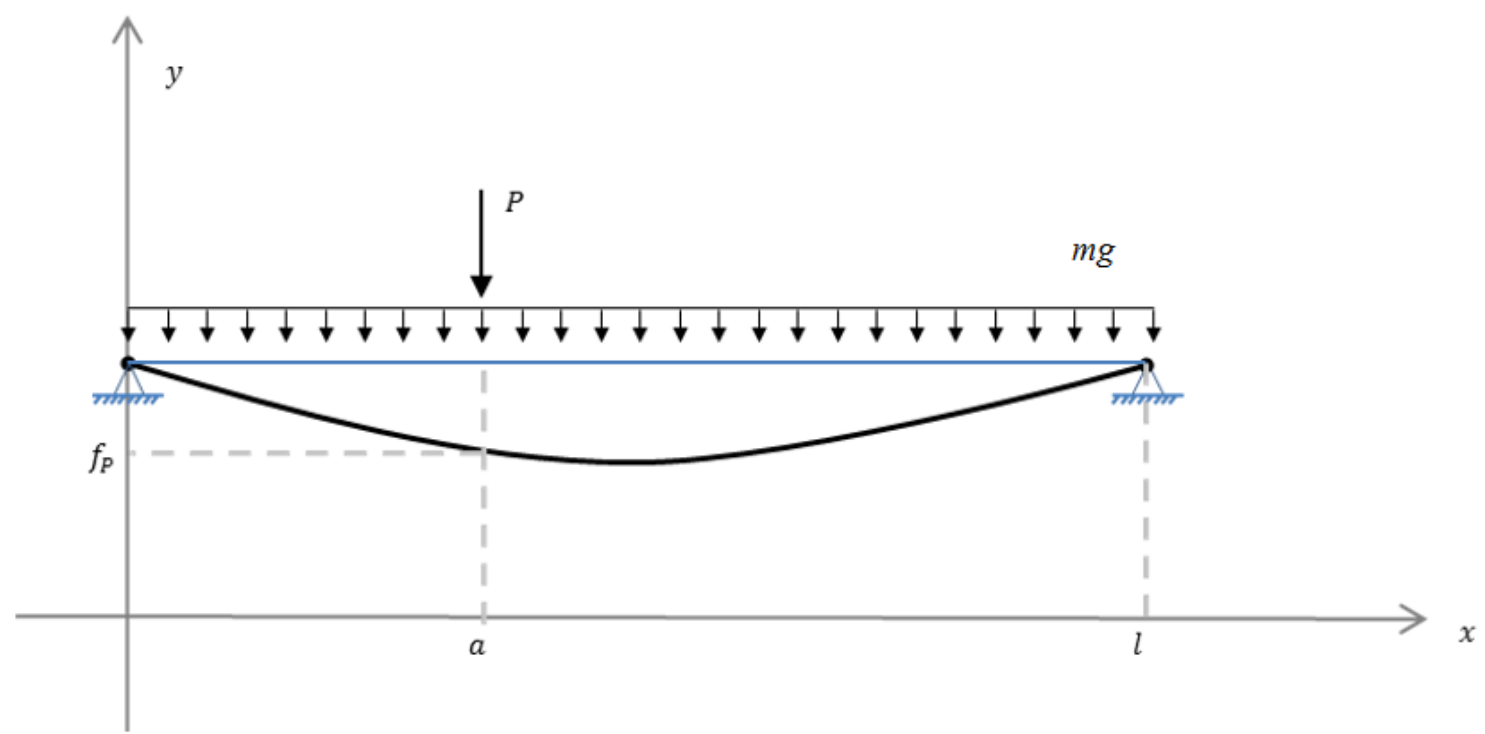

Figura 34 - Cabo suspenso com carga concentrada

Os seguintes dados foram considerados para análise:

$$
\begin{gathered}
L=304,8 m \\
a=121,92 \mathrm{~m} \\
A=5,48 \times 10^{-5} \mathrm{~m}^{2} \\
m g=46,09 \mathrm{~N} / \mathrm{m} \\
\rho=840851,140 \\
E=131,2 \mathrm{GPa}
\end{gathered}
$$

A Tabela 4 apresenta os resultados para $P=35,58 \mathrm{kN}$ 
Tabela 4 - Deslocamentos no ponto de aplicação da carga em metros

\begin{tabular}{|c|c|c|c|}
\hline & Jaymaran & NGL & dif. \% \\
\hline Vertical & 5,626 & 5,714 & $1,56 \%$ \\
\hline Horizontal & 0,859 & 0,870 & $1,25 \%$ \\
\hline
\end{tabular}

Este exemplo é importante para mostrar a evolução da resposta do cabo para o carregamento pontual. Pode-se observar a mudança da geometria do cabo quando a carga pontual aumenta. Verifica-se que no início da análise, para baixos valores de $\mathrm{P}$, grande parte do deslocamento é função da mudança da geometria enquanto que no final, quando a carga $P$ é significativa, e o cabo esticado, os deslocamentos são função principalmente das deformações elásticas.

Junto com a mudança de configuração observa-se um aumento na rigidez na direção do carregamento.

A Figura 35 mostra o diagrama de força por deslocamento no ponto de aplicação da carga. Também são destacados os pontos correspondentes às deformadas apresentadas na Figura 36.

Os dados para foram obtidos variando a carga aplicada $P$.

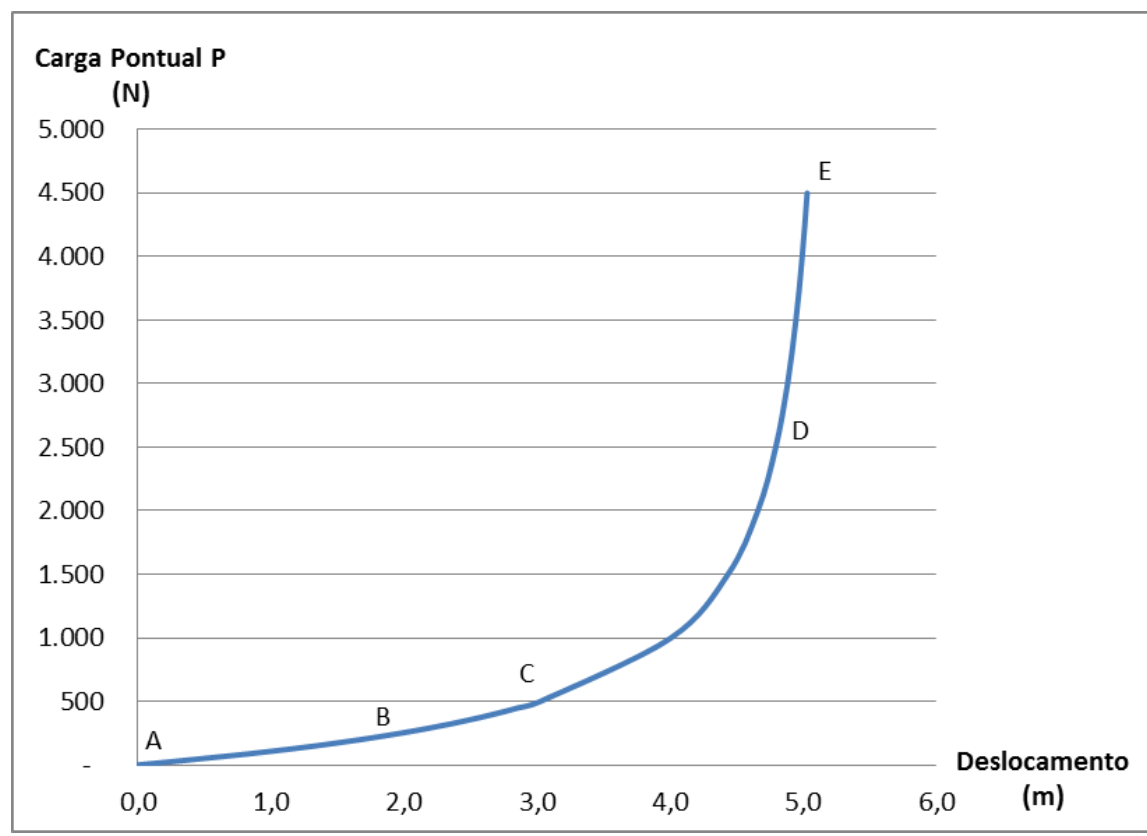

Figura 35 - Deslocamento do ponto de aplicação da carga 


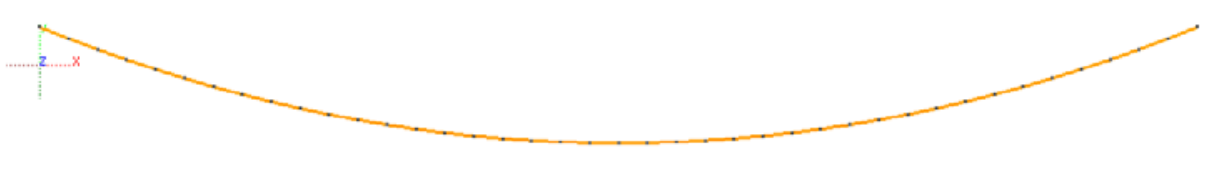

a) configuração do cabo com $P=0 N$

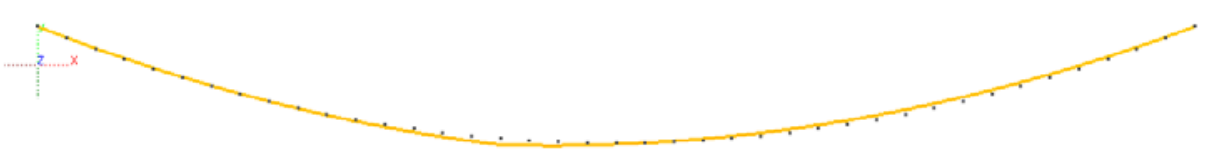

b) configuração do cabo com $P=250 \mathrm{~N}$

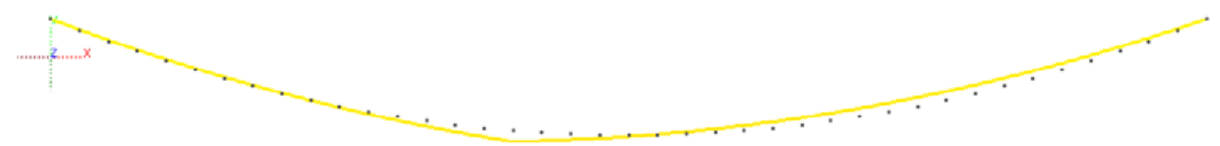

c) configuração do cabo com $P=500 \mathrm{~N}$

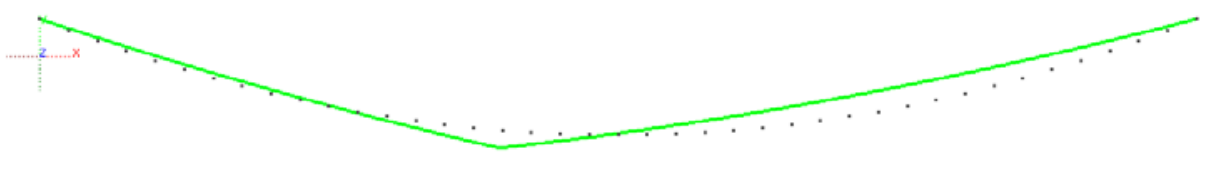

d) configuração do cabo com $P=2500 \mathrm{~N}$

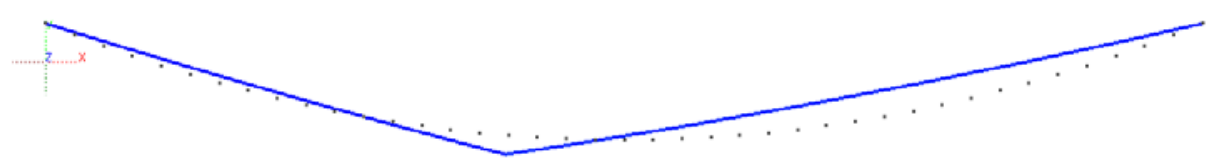

e) configuração do cabo com $P=4500 \mathrm{~N}$

Figura 36 - Deformada do cabo conforme aumento da carga pontual

Para a visualização das configurações deformadas e valores das tensões apresentados na Figura 36 foi utilizado o programa desenvolvido pelo departamento de estruturas da EESC, AcadView.

Os resultados dos modelos para os exemplos de verificação apresentaram pequenas diferenças entre os resultados obtidos por Jaymaran (1981). A modelagem do cabo em elementos de treliça com o programa não linear geométrico mostrou-se eficiente em representar o comportamento do cabo. 


\section{ESTUDO COMPARATIVO DA VARIAÇÃO DO MÓDULO DE RIGIDEZ EM FUNÇÃO DA INCLINAÇÃO DO CABO}

Neste estudo verificou-se a influência da inclinação do cabo na variação dos módulos de rigidez equivalentes estudados, o Módulo de Dischinger e a modificação proposta por Hajdin.

\subsection{OBTENÇÃO DO MÓDULO DE RIGIDEZ EQUIVALENTE COM OS MÓDULOS DE DISHINGER E HAJDIN}

Partindo de valores de tensão e vão pré determinados, foram adicionados incrementos de deslocamento na direção axial do elemento de cabo.

Ou seja, dados os valores da tensão inicial $T_{i}$ e comprimento do vão $l_{i}$ os módulos equivalente de Dishinger, $E_{e q, D}^{i}$, e Hajdin, $E_{e q, H}^{i}$, são calculados para dada configuração.

Um incremento $\Delta L_{i+1}$ é aplicado no elemento utilizando a rigidez do passo anterior para obtenção dos novos valores do módulo equivalente, assim é obtida a força de tração, $T_{i+1}$, para obtenção do modulo equivalente para o próximo incremento de carga, conforme equação (49).

$$
T_{i+1}=T_{i}+\frac{\Delta L_{i+1}}{L} E_{e q}
$$

Podendo $E_{e q}$ na equação (49) ser o módulo de Dishinger $E_{e q, D}$ ou Hajdin, $E_{e q, H}$.

Assim de posse dos novos valores de $T$ e $l$, projeção horizontal do cabo, são calculados os módulos de Dishinger, $E_{e q, D}^{i+1}$, e Hajdin, $E_{e q, H}^{i+1}$, para a próximo incremento de carga. 


\subsection{OBTENÇÃO DO MÓDULO DE RIGIDEZ EQUIVALENTE A PARTIR DO MODELO EM ELEMENTOS FINITOS}

A partir de uma configuração deformada do cabo é aplicado um deslocamento na direção longitudinal do eixo entre os dois apoios do cabo, conforme ilustra a Figura 37.

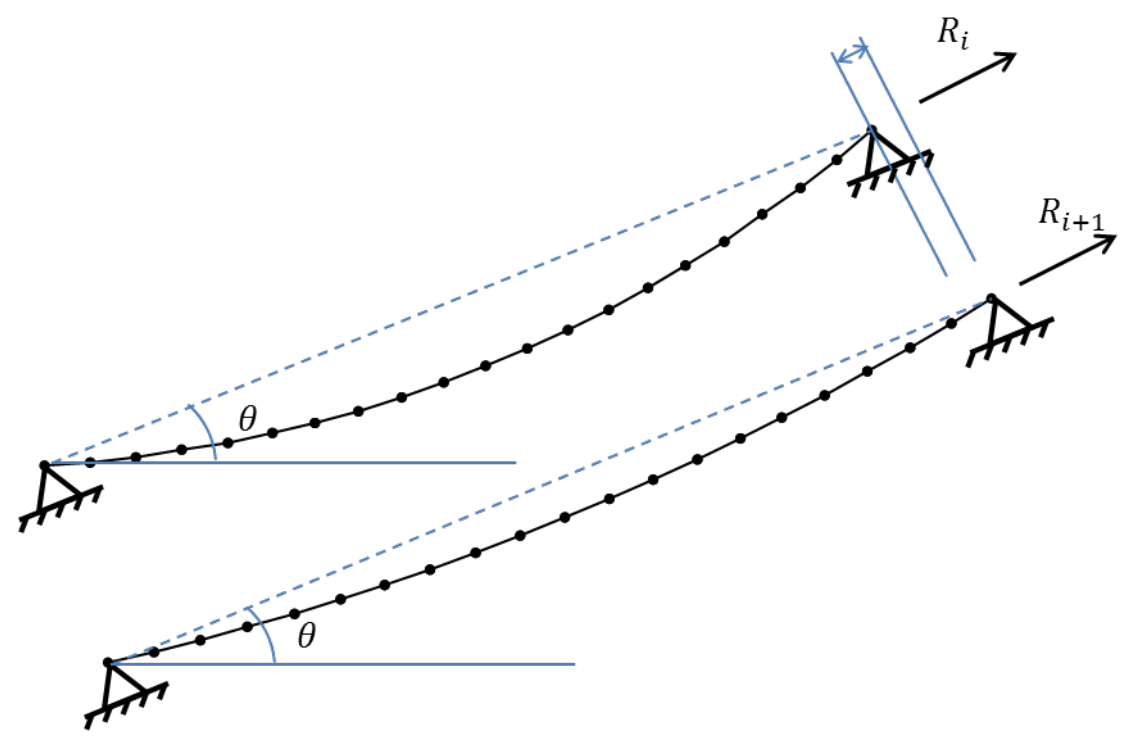

Figura 37 - Incremento de deslocamento no cabo do modelo em elementos finitos

A rigidez equivalente no modelo é obtida através da diferença entre a resultante das forças de reação na direção do eixo entre os apoios de extremidade, $\left(R_{i+1}-R_{i}\right)$, dividia pela área do cabo $A$ e pela deformação $\epsilon_{i}$, conforme equação (50).

$$
E_{e q, N L G}^{i+1}=\frac{\left(R_{i+1}-R_{i}\right)}{\epsilon_{i}}
$$

Onde $e_{i}$ é a deformação da reta entre os apoios do cabo dada pela equação (51). 


$$
\epsilon_{i}=\frac{l_{i+1}-l_{i}}{l_{i}}
$$

\subsection{AVALIAÇÃO DOS RESULTADOS}

Os gráficos a seguir mostram a relação do módulo de elasticidade efetivo com o módulo de elasticidade equivalente obtida a partir das três formas propostas neste trabalho. O estudo é feito comparando os valores obtidos com diferentes inclinações $\theta$, em relação ao plano horizontal.

Para $\theta=0^{\circ}$, os resultados obtidos com o módulo de Dischinger e com o módulo de Hajdin são idênticos, pois conforme demonstrado no item 3.4 deste trabalho $E_{e q, H}=E_{e q, D}$ quando $g_{x}=0$.

A Figura 38 apresenta os resultados para $\theta=0^{\circ}$.

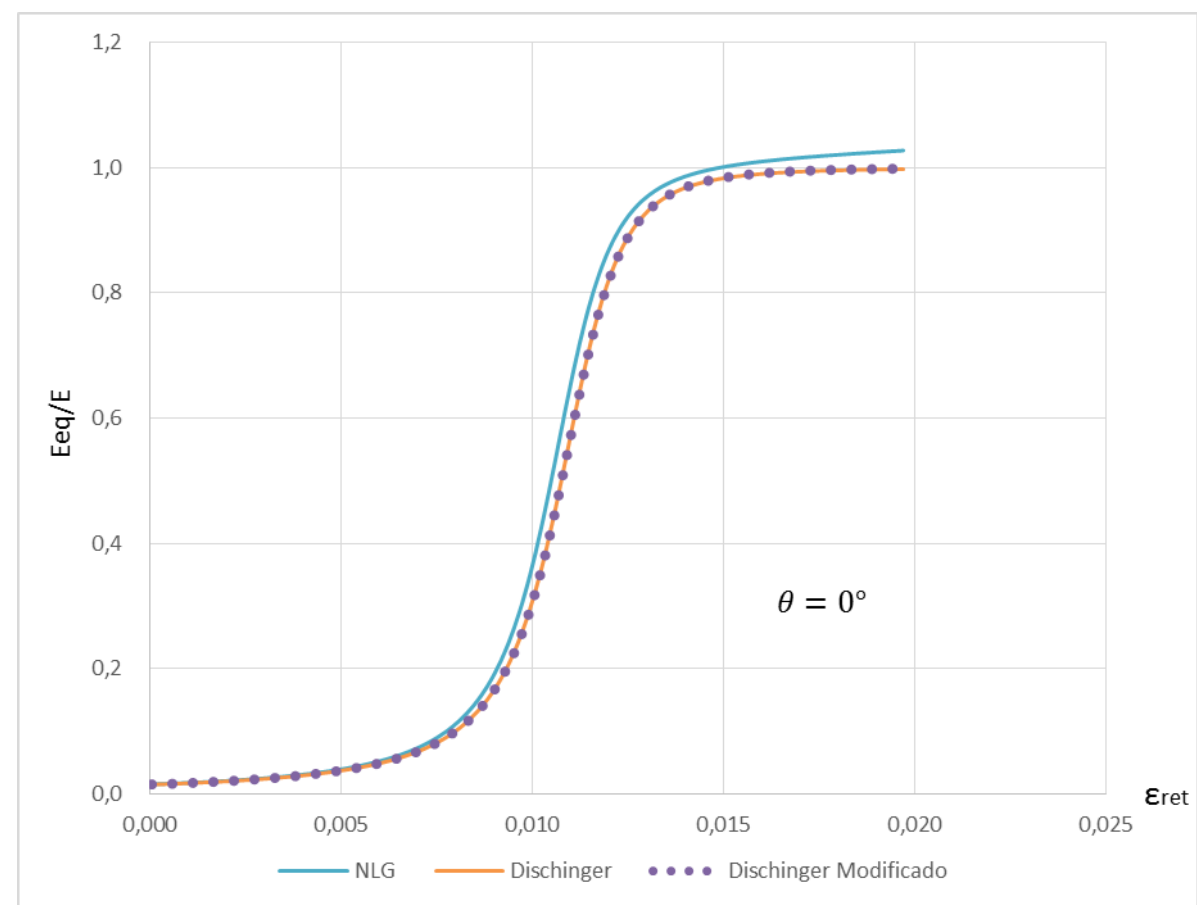

Figura 38 - Variação do módulo de rigidez equivalente para inclinação $0^{\circ}$ 
Ainda na Figura 38 é possível observar que a diferença é pequena em relação ao modelo não linear geométrico NLG, com valor médio em torno de $2 \%$.

Com $\theta=10^{\circ}$ já se percebe uma diferença entre Hajdin e Dischinger, em torno de $30 \%$, conforme pode se observar no gráfico da Figura 39

Já entre Hajdin e o modelo NLG a diferença é menor com valor máximo de $2,7 \%$

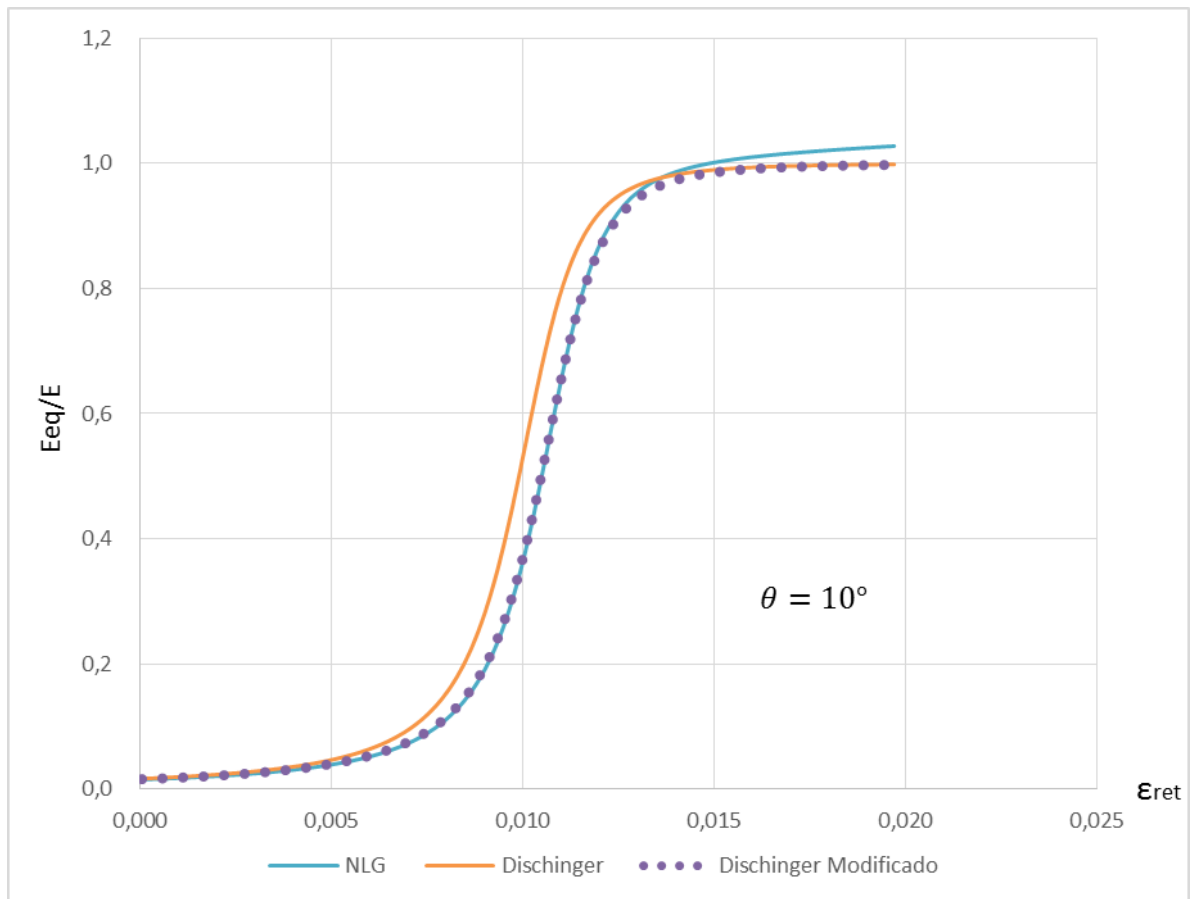

Figura 39 - Variação do módulo de rigidez equivalente para inclinação $10^{\circ}$

A partir de $\theta=20^{\circ}$ observa-se que a diferença entre Dishinger e Hajdin chega a 90\%, conforme pode ser visto nos resultados apresentados nas figuras Figura 40 e na Figura 41 para $\theta=30^{\circ}$.

Quando $\theta=20^{\circ}$ a diferença entre Hajdin e o NLG é de no máximo 21,3\%. 


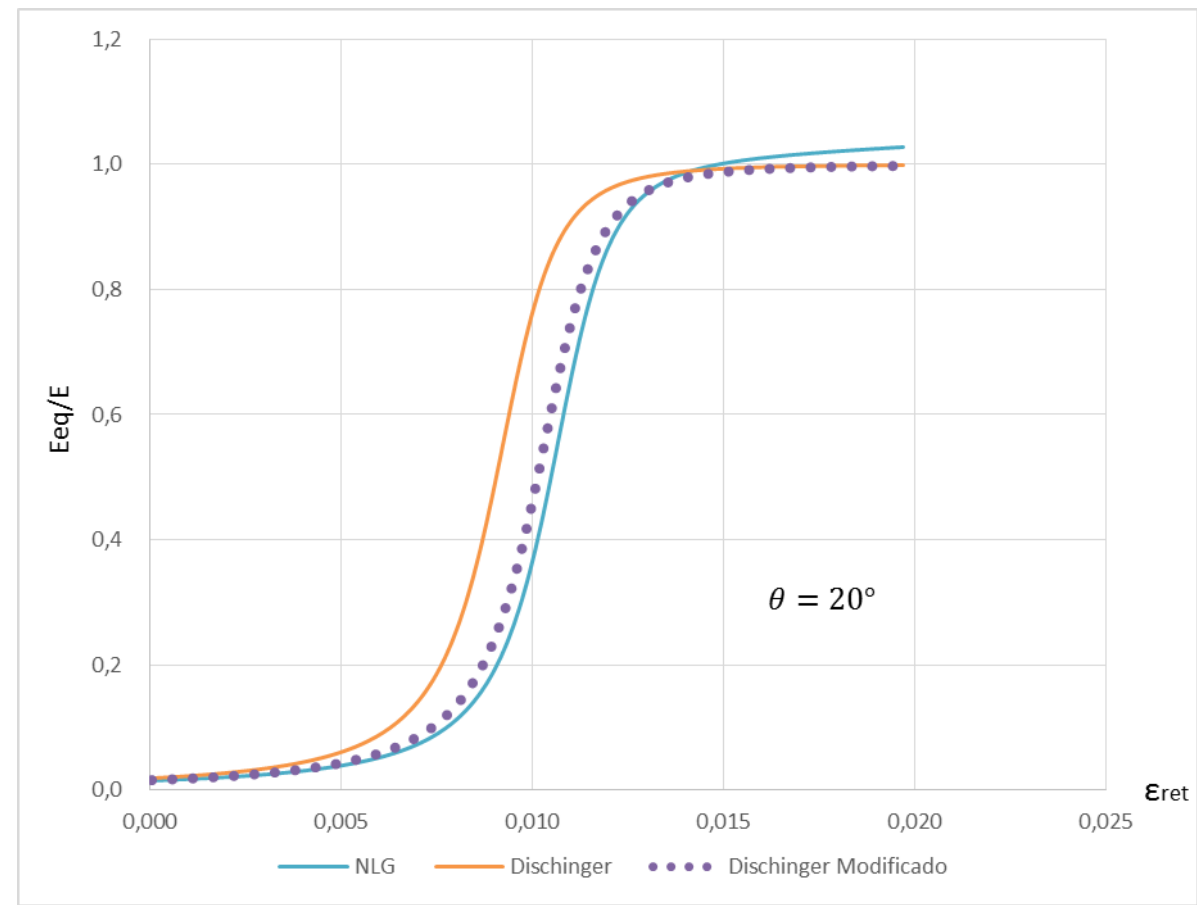

Figura 40 - Variação do módulo de rigidez equivalente para inclinação $20^{\circ}$

Para $\theta=30^{\circ}$ a diferença entre Hajdin e o NLG é de no máximo 39\%.

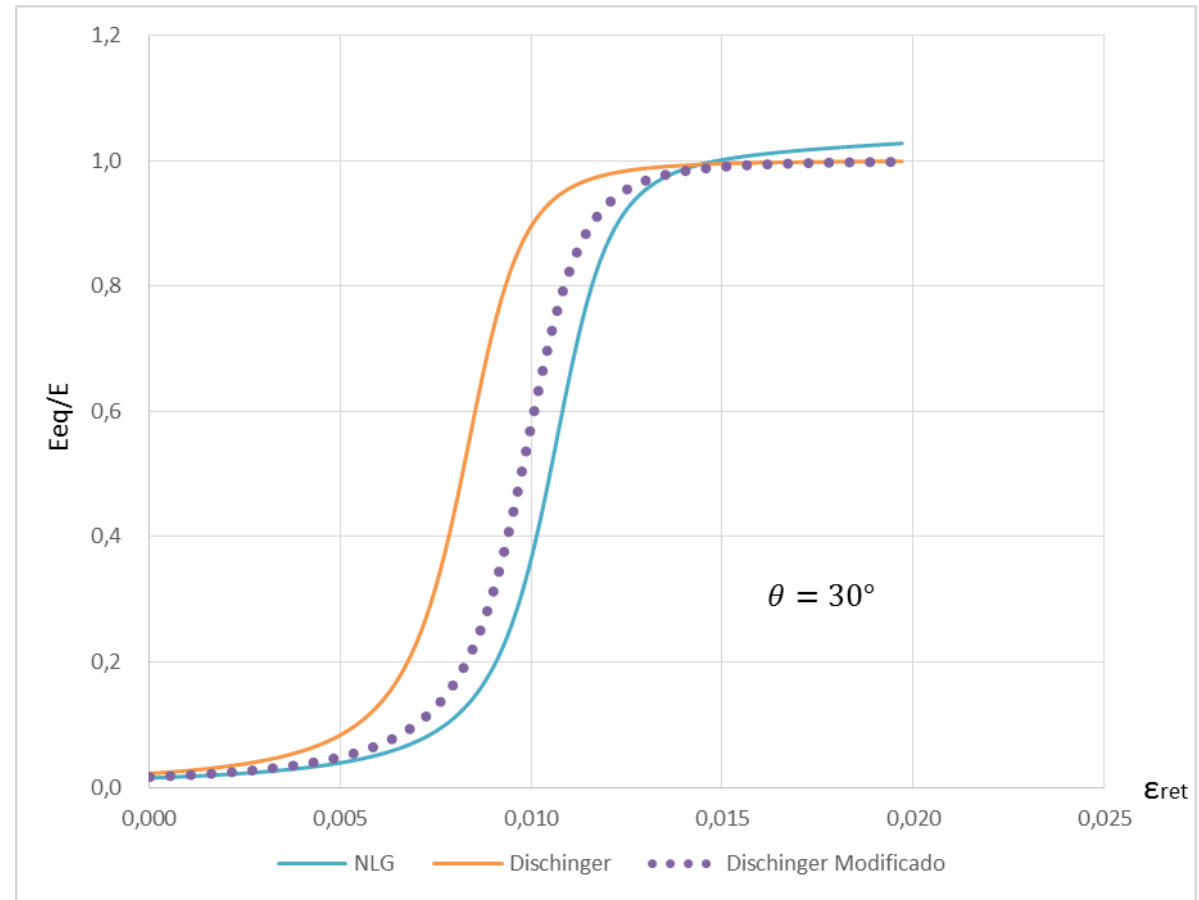

Figura 41 - Variação do módulo de rigidez equivalente para inclinação $30^{\circ}$ 
A partir de $\theta=45^{\circ}$ percebe-se um distanciamento maior entre os modelos estudados e a diferença chega a ser maior que $90 \%$.

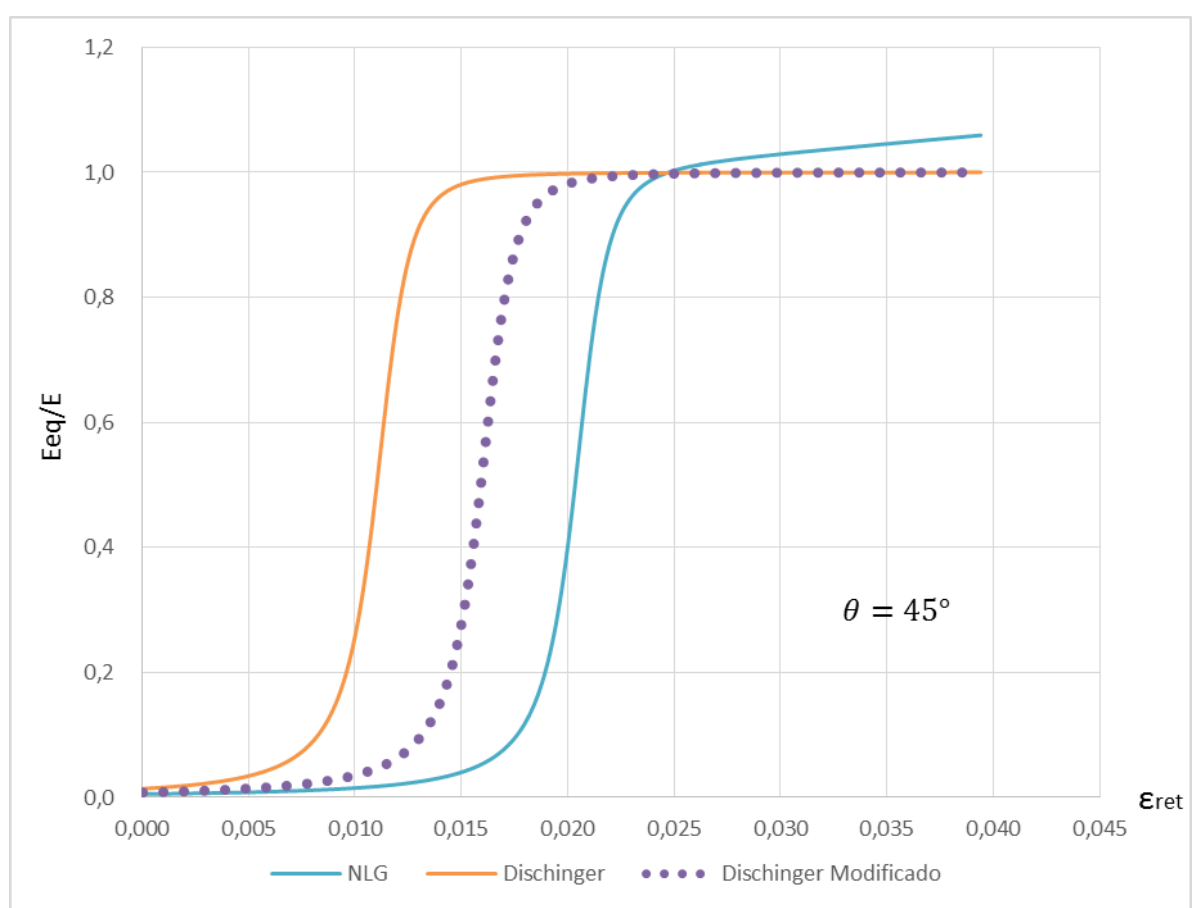

Figura 42 - Variação do módulo de rigidez equivalente para inclinação $45^{\circ}$

Para $\theta=60^{\circ}$, Figura 43 e $\theta=75^{\circ}$, Figura 44 , observa se um distanciamento grande do momento em que a rigidez do cabo chega ao seu valor efetivo. 


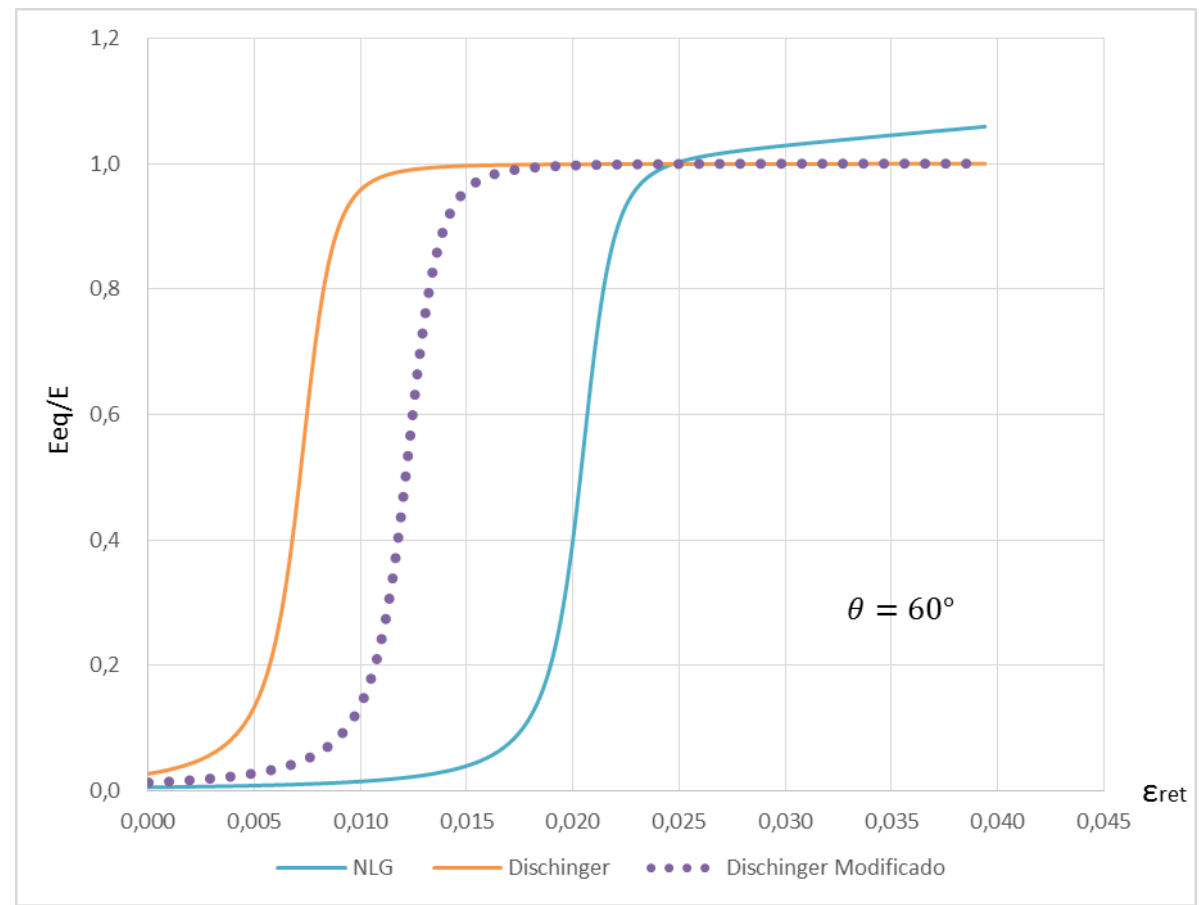

Figura 43 - Variação do módulo de rigidez equivalente para inclinação $60^{\circ}$

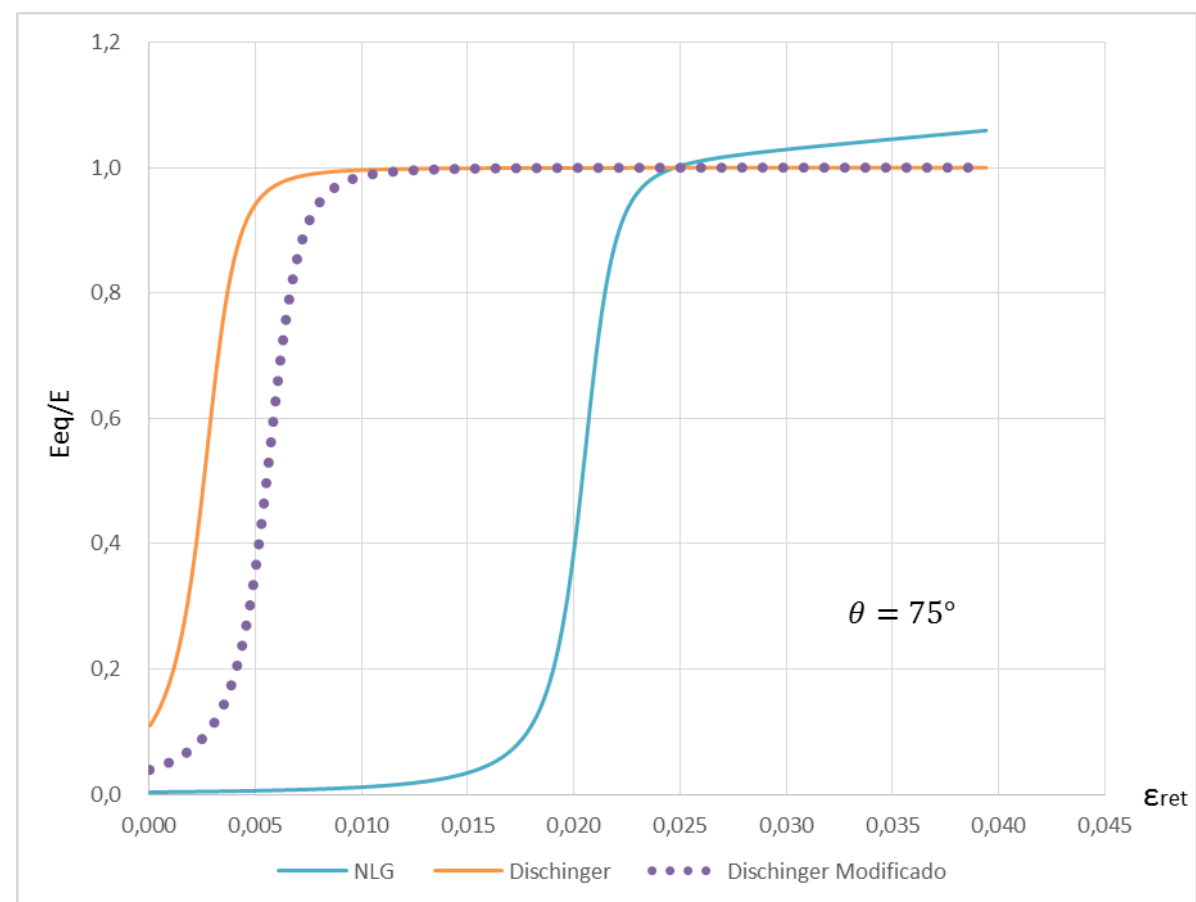

Figura 44 - Variação do módulo de rigidez equivalente para inclinação $75^{\circ}$ 


\section{CONCLUSÕES}

A modelagem do cabo com a Formulação Posicional dos Elementos Finitos com elementos de treliça se mostrou satisfatória para análise de comportamento do cabo isolado.

Porém o processo de modelagem do cabo discretizado em elementos de treliça se torna exaustivo e oneroso em termos computacionais quando para simulação de estruturas mais complexas como as pontes estaiadas.

Muitos estudos e projetos foram realizados com a utilização do módulo de Dischinger, com bons resultados verificados em campo, como apresenta Hajdin (2000).

Com as simulações realizadas, tendo como parâmetro de comparação os resultados com a modelagem na formulação posicional, pode-se observar que a formulação proposta por Hajdin, que considera a componente do peso próprio tangencial ao cabo, melhora significativamente a aproximação do cabo para um elemento de treliça com módulo de rigidez equivalente.

A implementação da formulação de Hajdin, comparada a original de Dischinger, adiciona apenas uma operação ao cálculo da rigidez equivalente, e não tem um custo computacional alto, portanto pode ser implementada facilmente inclusive em algoritmos prontos com a formulação de Dischinger.

Em ângulos próximos de zero, a diferença chega a ser pequena, porém, não é muito aplicável em pontes estaiadas, já que há uma perda significativa da eficiência do cabo quanto menor for a inclinação do mesmo, devido ao aumento da flecha e perda de rigidez.

A partir de $\theta>45^{\circ}$ o efeito da deformação dos elemento começa a influenciar bastante nos resultados, o que pode justificar o distanciamento ocorrido entre os resultados do modelo NLG e dos modelos de Dischinger e Hajdin, já que os mesmo partem da formulação parabólica para descrever o cabo e não considera a deformação elástica do cabo.

Também foi observado um aumento do valor da rigidez equivalente do cabo, acima do valor da rigidez efetiva do elemento, no modelo NGL. Este efeito a 
princípio foi atribuído a efeitos de segunda ordem devido ao carregamento que não são considerados nas formulações propostas por Dischinger e Hajdin.

Segue como sugestão de continuidade a verificação de outras formulações para elementos de cabo, avaliando a capacidade de cada elemento de simular o comportamento do cabo tanto estático quanto dinâmico, e a influência no esforços globais de uma estrutura estaiada. 


\section{REFERÊNCIAS BIBLIOGRÁFICAS}

BILLINGTON, David. P. "History and aesthetics of cable-stayed bridges." Journal of Structural Engineering, v. 117, no. 10, 3103-3117. Virginia: ASCE. 1990.

CODA, H. B. "Introdução à dinâmica não linear de estruturas reticuladas bidimensionais: uma abordagem energética baseada no método dos elementos finitos". (notas de aula), 2010.

CODA, H. B. "Nonlinear Positional formulation for space truss analysis". Finite Elements in Analysis and Desing, v. 42, 1079-1086. Amsterdam: Elsevier Science Ltd, 2006.

DISCHINGER, F. "Hängebruken für schwerste Verkehrslasten." Der Bauingenieur, v. 24, 66-113. Düsseldorf: Springer-VDI-Verlag GmbH \& Co. KG 1949.

ERNST, H. J. "Der E-Modul von seilen unter Berücksichtigung des Durchhanges", Der Bauingenieur, v. 40, 52-55. Düsseldorf: Springer-VDI-Verlag GmbH \& Co. KG. 1965.

FLEMMING, J. F. "Nonlinear static analysis of cable stayed structures." Computer \& Structures, v. 10, 621-635, Great Britain: Pergamon Press Ltd. 1979.

GIMSING, N. J., GEORGAKIS, C. T., Cable supported bridges: concept and design. London. John Wiley \& Sons, Ldt. 2012 - 3a Edição

GRECO, M. CODA, H. B. "Positional FEM formulation for flexible multi-bodydynamic analysis", Journal of Sound and Vibration, V 290, 1141-1174. Amsterdam: Elsevier Science Ltd. 2005.

HAJDIN, N., MICHALTSOS, G. T., KONSTANTAKOPOULOS, T. G. "About the equivalent modulus of elasticity of cable-stayed bridges." Scientific Journal Facta Universitatis, v. 1 - 5, 569 - 575, Dusan Ilic: Dragan Velickovic. 2000.

IRVINE, H. M. Cable Structures. New York: Dover Publications. 1992. 
JAYMARAN, H. B., KNUDSON, W. C. "A curved element for the analysis of cable structures", Computer \& Structures, v. 14, 325-333, Great Britain: Pergamon Press Ltd. 1981.

MAZARIM, D. M. Histórico das pontes estaiadas e sua aplicação no Brasil. São Paulo: Dissertação de Mestrado, POLI-USP. 2011.

PAULETTI, R. M. de O. História, Análise e Projeto das Estruturas Retesadas. São Paulo: Tese de Livre-Docência, POLI-USP. 2003.

PEYROT, A. H., GOULOIS, A. M., "Analysis of cable structures", Computer \& Structures, v. 10, 805-813. Great Britain: Pergamon Press Ltd. 1978.

POLDONY, W., SCALZI, J. B., Construction and design of cable-stayed bridges. New York: John Wiley \& Sons, Ldt. 1976.

TROITSKY, M. S. Cable stayed bridges. Oxford: BSP Professional Books. 1988.

VIRLOGEUX, M. "Recent evolution of cable-stayed bridges", Engineering Structures, V. 21, 737-755. Amsterdam: Elsevier Science Ltd. 1999.

WANG, P. H., "Initial shape of cable-stayed bridges." Computer \& Structures, v. 46, 1095-1106, Great Britain: Pergamon Press Ltd. 1993.

WANG, P. H., "Parametric Studies on Cable-stayed Bridges." Computer \& Structures, v. 60, 243-260, Great Britain: Pergamon Press Ltd. 1995.

YTZA, M. F.Q. Métodos construtivos de pontes estaiadas: estudo da distribuição de forças nos estais. São Paulo: Dissertação de Mestrado POLI-USP. 2009.

Entrevista com Gilberto Barbosa do Valle - Presidente da ABPE (Associação Brasileira de Pontes e Estruturas) disponível em: http://www.cimentoitambe.com.br/massa-cinzenta/pontes-estaiadas-novidades-nobrasil/. Acesso em 12/10/2010. 